\title{
Getting into the brain: liposome-based strategies for effective drug delivery across the blood-brain barrier
}

This article was published in the following Dove Press journal:

International Journal of Nanomedicine

18 October 2016

Number of times this article has been viewed

\author{
Débora B Vieira' \\ Lionel F Gamarra ${ }^{1,2}$ \\ 'Hospital Israelita Albert Einstein, São \\ Paulo, Brazil; ${ }^{2}$ Faculdade de Ciências \\ Médicas da Santa Casa de São Paulo, \\ São Paulo, Brazil
}

\begin{abstract}
This review summarizes articles that have been reported in literature on liposome-based strategies for effective drug delivery across the blood-brain barrier. Due to their unique physicochemical characteristics, liposomes have been widely investigated for their application in drug delivery and in vivo bioimaging for the treatment and/or diagnosis of neurological diseases, such as Alzheimer's, Parkinson's, stroke, and glioma. Several strategies have been used to deliver drug and/or imaging agents to the brain. Covalent ligation of such macromolecules as peptides, antibodies, and RNA aptamers is an effective method for receptortargeting liposomes, which allows their blood-brain barrier penetration and/or the delivery of their therapeutic molecule specifically to the disease site. Additionally, methods have been employed for the development of liposomes that can respond to external stimuli. It can be concluded that the development of liposomes for brain delivery is still in its infancy, although these systems have the potential to revolutionize the ways in which medicine is administered.
\end{abstract} Keywords: Alzheimer, Parkinson, stroke, cerebral ischemia, glioma, liposomes, blood-brain barrier

\section{Introduction}

In the 1880s, Paul Ehrlich intravenously injected dyes (eg, trypan) into animals, and observed that the dyes were able to stain all organs except for the brain. He concluded that the brain had a lower affinity to the dye when compared to other organs. ${ }^{1}$ In 1913 , Edwin Goldmann, a student of Ehrlich, did the opposite, and injected the very same dyes directly to the cerebrospinal fluid of animal brains. He found that in this case, the dyes readily stained the brain and not the other organs. ${ }^{2}$ These experiments clearly demonstrated the existence of a separation between the blood and the brain. However, in 1898, Max Lewandowsky was the first to postulate the existence of a specialized barrier at the level of cerebral vessels: the blood-brain barrier (BBB), after he and his colleagues had carried out some experiments to demonstrate that some drugs were neurotoxic when injected directly into the brain and not into the vascular system. ${ }^{3}$ It was just in the late 1960s that Reese and Karnovsky visualized the fact that the barrier was localized to the endothelium by electron-microscopy studies. ${ }^{4}$

The BBB is composed of polarized endothelial cells connected by tight junctions of the cerebral capillary endothelium and a variety of transporters (Figure 1), which are responsible for its extremely low permeability, limiting the delivery of drugs to the central nervous system (CNS) ${ }^{5,6} \mathrm{BBB}$ functionality is dynamically regulated by an ensemble of different cell types, such as astrocytes, pericytes, and neurons (Figure 1A). ${ }^{7-9}$ 


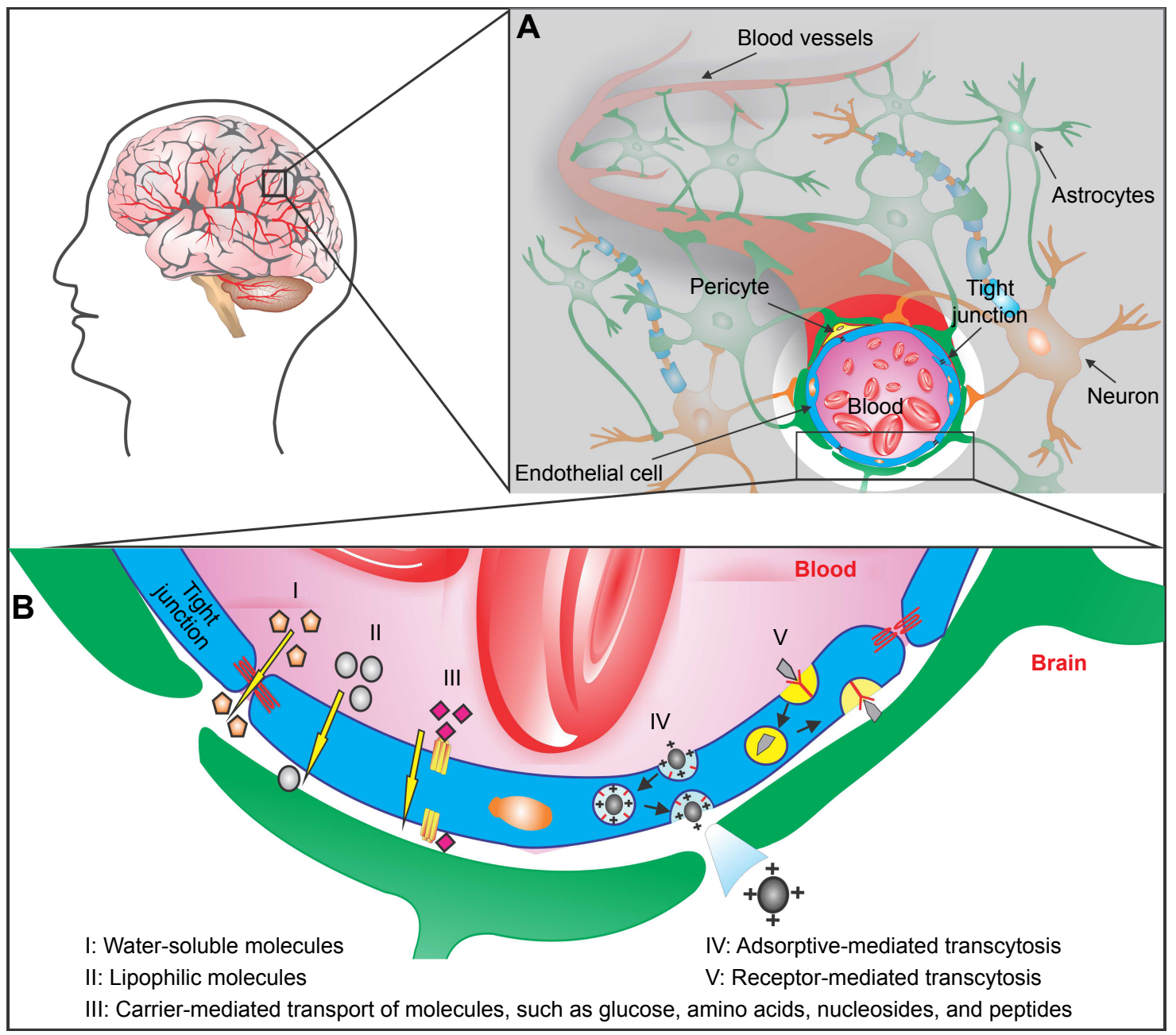

Figure I Pathways for crossing the blood-brain barrier (BBB).

Notes: The BBB is located at the walls of the blood vessels that supply the central nervous system, including the brain. (A) Cross-section of a cerebral capillary, showing the structure of the BBB. The barrier is composed of a network of astrocytes, pericytes, neurons, and endothelial cells that form the tight junctions. (B) Different mechanisms for drug delivery across the BBB: water-soluble molecules penetrate the BBB through the tight junctions (I); lipid-soluble molecules are able to diffuse across the endothelial cells passively (II); carrier-mediated transport machineries are responsible for transporting peptides and small molecules (III); cationic drug increases its uptake by adsorptivemediated transcytosis or endocytosis (IV); larger molecules are transported through receptor-mediated transcytosis (V).

Endothelial cells are surrounded by a basal lamina, which is generally rich in laminin, fibronectin, type IV collagen, and heparin sulfate, ${ }^{5,7-9}$ which may represent an interesting targeting for drug transport and provides a negatively charged interface. ${ }^{10,11}$

Aimed at the development of more efficient therapies for neurological disorders, extensive research is being done into the molecular and cell biology of many of these disorders. To date, human genetic mutations and defective cell-signaling pathways linked to a disease have been identified, and may contribute to the development of mechanism-based therapies and biomarkers for affected patients at early stages in the disease. ${ }^{12,13}$ Moreover, pharmaceutical companies have spent billions of dollars in the hope that their scientists could develop drugs to defeat the brain disorders, eg, a drug that helps brain-cell growth, repairs damage, or slows down tumor progress, something that is not available now. However, obstacles to effective therapy delivery remain, and one of the most notable obstacles for drugs to penetrate the brain effectively is the BBB. ${ }^{14,15}$

\section{How to circumvent the blood-brain barrier?}

Based on better knowledge of BBB biology, several different strategies for delivering molecules across the barrier have been developed for treating CNS diseases, and can be broadly classified as invasive, pharmacological, and physiological approaches. ${ }^{15-19}$ The invasive method is based on direct delivery of drugs into the brain tissue through varying techniques, such as the use of polymers or microchip systems, 
stereotactically guided drug insertion through a catheter, and transient disruption of the BBB. However, these approaches are invasive, leading to risks of infection, damage to brain tissue, and toxicity. Furthermore, invasive approaches are costly and require hospitalization..$^{20-22}$

The pharmacological method for crossing the BBB is based on modifying, through medicinal chemistry, a drug molecule to enable BBB permeability and making it insusceptible to drug-efflux pumps, such as P-glycoprotein (PgP). ${ }^{17}$ One early strategy was based on the development of highly lipophilic and small drugs, allowing them to diffuse successfully through the brain's endothelial cells (Figure 1B). Unfortunately, synthesizing drugs that fulfill this condition eliminate a vast number of potentially useful polar molecules that could be used to treat CNS disorders. A second possibility is to use small water-soluble drugs to facilitate traversal of the BBB by the paracellular hydrophilic diffusion pathway (Figure 1B), though the majority of these molecules are just able to penetrate the interendothelial space of the cerebral vasculature up to the tight junctions, and not beyond. Moreover, modifications to drug structure often result in loss of the drug's biological activity. ${ }^{23}$

Among all the approaches employed in drug delivery to the brain tissues, the physiological method is the most advantageous, as it takes advantage of the transcytosis capacity of specific transporting receptors expressed at the BBB surface in order to penetrate the barrier (Figure 1B). For example, the occurrence of low-density lipoprotein receptor-related protein on the $\mathrm{BBB}$ is of critical importance for therapeutic proteins or peptides to glial cells or neurons across the whole CNS. ${ }^{24-26}$ Another method consists in the use of receptor-mediated endocytosis by conjugation of drug molecules to ligands, such as antibodies and peptides, against receptors that are expressed on the surface of endothelial cells of the barrier, ${ }^{6}$ allowing the drug to be transported into the brain (Figure 1B). In addition, cationic compounds are able to bind to the negatively charged plasma membrane of the endothelial cells by electrostatic interactions. ${ }^{10,11}$ Therefore, the cationic substance crosses the BBB by adsorptionmediated transcytosis or endocytosis (Figure 1B). However, a low rate of drug dissociation from the ligands, nonspecific drug-receptor interactions, and the limited concentration of cationic substances in the brain are disadvantages for this kind of approach.

Undoubtedly, all three of these approaches have strong disadvantages that limit the successful treatment of neurological diseases. In response to this insufficiency in methods to transport therapeutic drugs across the $\mathrm{BBB}$, aggressive research efforts into the use of nanotechnology to deliver drugs effectively across the BBB without altering their effect is being done. For this purpose, a broad range of nanoparticles with different sizes, architectures, and surface properties have been engineered for brain drug delivery. ${ }^{27,28}$ These include liposomes, ${ }^{29,30}$ polymeric nanoparticles, ${ }^{31,32}$ carbon nanotubes,${ }^{33,34}$ nanofibers, ${ }^{35,36}$ dendrimers, ${ }^{37,38}$ micelles,${ }^{39}$ inorganic nanoparticles made of iron oxide, ${ }^{40}$ and gold nanoparticles. ${ }^{41}$ Unfortunately, it is beyond the scope of this article to review potential advantages - or disadvantages - of each of these nanocarriers in the imaging and/or therapy of the brain. For a more detailed overview of nanotechnologybased systems on drug delivery to the CNS, we refer the reader to Vlieghe and Khrestchatisky. ${ }^{27}$ Here we focus on the one of most promising approaches aimed at improving brain drug targeting and delivery: liposomes and molecules that can selectively target brain tissues. In fact, liposomes are at present the nanoparticle type with the most studies that have been published for delivery to the brain, representing in this way the most advanced material and thus with the highest potential for clinical applications.

\section{Why use liposomes for treating neurological disorders?}

Common diseases of the CNS, such as neurodegeneration, multiple sclerosis, stroke, and brain tumors, represent a huge medical need. According to a World Health Organization report, about 1.5 billion people globally are suffering from neurological diseases..$^{42}$ The prevalence of neurological disorders is expected to have a significant increase in the next decade, as the aging population is highly increasing and living longer. Drug therapies to the brain have been particularly inefficient, especially due to the BBB, as discussed earlier. It would be thus be desirable to gain a better understanding of the molecular mechanism of the disease and the development of improved diagnostic devices and treatments. In this way, liposomes have emerged as promising carriers for CNS delivery.

Liposomes are roughly nano- or microsize vesicles consisting of one or more lipid bilayers surrounding an aqueous compartment. The potential use of these vesicles as a carrier system for therapeutically active compounds was recognized soon after its discovery in the early 1960s. In recent years, liposomes have been explored as carriers of therapeutic drugs, imaging agents, and genes, in particular for treatment and/or diagnosis of neurological diseases. ${ }^{29,43-45}$ Due to their unique physicochemical characteristics, liposomes are able to incorporate hydrophilic, lipophilic, and 


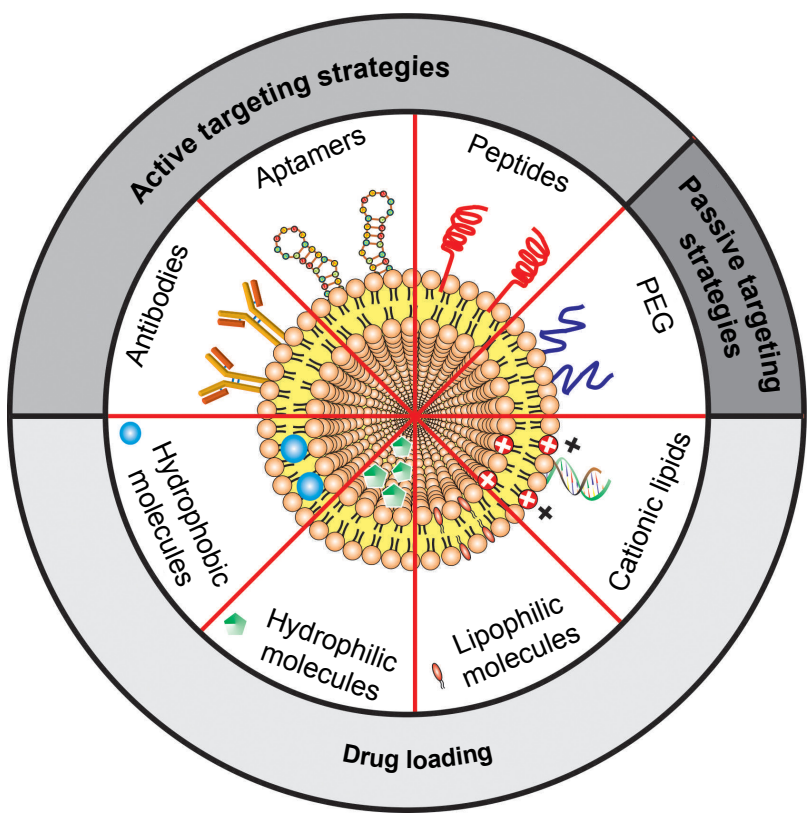

Figure 2 Schematic representation of the main liposomal drugs and targeting agents that improve liposome affinity and selectivity for brain delivery.

Abbreviation: PEG, polyethylene glycol.

hydrophobic therapeutic agents. Hydrophilic compounds may either be entrapped into the aqueous core of the liposomes or be located at the interface between the lipid bilayer and the external water phase. Lipophilic or hydrophobic drugs are generally entrapped almost completely in the hydrophobic core of the lipid bilayers of the liposomes. In addition, the use of cationic lipids allows the adsorption of polyanions, such as DNA and RNA (Figure 2). They also have the advantage of presenting good biocompatibility and biodegradability, low toxicity, drug-targeted delivery, and controlled drug release. ${ }^{46,47}$ In order to improve blood circulation and brain-specific delivery, the liposome surface can be further modified by the inclusion of macromolecules, such as polymers, polysaccharides, peptides, antibodies, or aptamers (Figure 2). Unfortunately, efficient brain-specific drug delivery by liposomes is not in clinical practice. However, several liposomal drugs are either approved for clinical use or in clinical trial studies (Table 1). ${ }^{48-59}$

Optimizing the ideal liposome for crossing the BBB has important implications for the treatment of neurological diseases. Different liposomal formulations and strategies have been developed for enhancing drug delivery across the BBB. The following examples illustrate current strategies using liposomes as brain vectors (Table 2). ${ }^{60-69}$ Cationic liposomes are successfully used as carriers for the delivery of therapeutic drugs and genes. ${ }^{70-72}$ Several studies have shown that these cationic nanocarriers are more efficient vehicles for drug delivery to the brain than conventional, neutral, or anionic liposomes, possibly due to the electrostatic interactions between the cationic liposomes and the negatively charged cell membranes, enhancing nanoparticle uptake by adsorptive-mediated endocytosis. ${ }^{60-62}$ But there is a major drawback to the use of cationic nanocarriers for brain delivery: due to nonspecific uptake by peripheral tissues and their binding to serum proteins that attenuates their surface charge, large amounts of these nanocarriers will be required to reach therapeutic efficacy, and those carriers are potentially cytotoxic. Therefore, there is a need for the development of liposomes that efficiently target diseased areas in the brain.

Surface-functionalization methodologies improve, at least in part, the pharmacokinetics and biodistribution of liposomes into the brain. For example, the addition of polyethylene glycol (PEG) or polysaccharides forms a protective layer over the surface of liposomes and protects the vehicle from the binding of plasma proteins, preventing the opsonization process and subsequent clearance of liposomes. Even though the PEGylation of liposomes prolongs their circulation time in the body, it does allow liposomes to cross the BBB. Therefore, their functionalization with biologically active ligands, such as peptides, antibodies, aptamers, and others, which specifically bind to receptors that are expressed

Table I Liposome-based drugs on market or in clinical trials for brain-targeted drug delivery

\begin{tabular}{|c|c|c|c|c|c|}
\hline $\begin{array}{l}\text { Commercial } \\
\text { name }\end{array}$ & Compound & Lipid composition & Indications & Trial phase & References \\
\hline AmBisome & Amphotericin B & HSPC, DSPG, and cholesterol & Cryptococcal meningitis & NA & 48,49 \\
\hline Abelcet $^{\circledR}$ & Amphotericin B & DMPC and DMPG & Cryptococcal meningitis & NA & 48,49 \\
\hline DaunoXome ${ }^{\circledR}$ & Daunorubicin & DSPC and cholesterol & Pediatric brain tumors & 1 & 50 \\
\hline Depocyt $^{\circledR}$ & Cytarabine & Cholesterol, triolein, DOPC, and DPPG & Lymphomatous meningitis & NA & 51 \\
\hline \multirow[t]{2}{*}{ Doxil ${ }^{\circledR} /$ Caelyx $x^{\circledR a}$} & Doxorubicin & HSPC, cholesterol, and DSPE-PEG ${ }_{2,000}$ & Glioblastoma multiforme & II & $52-55$ \\
\hline & & & Pediatric brain tumors & II & 56,57 \\
\hline Myocet $^{\circledR}$ & Doxorubicin & EPC and cholesterol & Glioblastoma multiforme & II & 58 \\
\hline
\end{tabular}

Note: aPEGylated liposomal doxorubicin is known as Doxil ${ }^{\circledR}$ in the US and Caelyx ${ }^{\circledR}$ in Europe.

Abbreviations: DMPC, dimyristoylphosphatidylcholine; DMPG, dimyristoylphosphatidylglycerol; DOPC, dioleoylphosphatidylcholine; DPPG, dipalmitoylphosphatidylglycerol; DSPC, distearoylphosphatidylcholine; DSPE, distearoylphosphatidylethanolamine; DSPG, distearoylphosphatidylglycerol; EPC, egg Phosphatidylcholine; HSPC, hydrogenated soy phosphatidylcholine; NA, not applicable; PEG, polyethylene glycol. 
Table 2 Means by which liposomes can penetrate the BBB

\begin{tabular}{|c|c|c|}
\hline Strategies to permeate the BBB & Short description & References \\
\hline ionization of the vector & $\begin{array}{l}\text { The use of cationic liposomes is an interesting strategy, due to electrostatic } \\
\text { interaction between their positive charges and the polyanions present at the } \\
\text { BBB, resulting in adsorptive-mediated endocytosis. }\end{array}$ & $60-62$ \\
\hline$y=$ & $\begin{array}{l}\text { To increase liposomal drug accumulation into the brain, the use of ligand- } \\
\text { targeted liposomes toward the receptors expressed on brain endothelial } \\
\text { cells has been suggested, resulting in receptor-mediated transcytosis. One } \\
\text { or more targeting ligands, such as antibodies and aptamers, can be covalently } \\
\text { bound over the liposome surface or to the ends of the PEG chains. }\end{array}$ & $44,63-65$ \\
\hline $\begin{array}{l}\text { Chemical, } \\
\text { physical, or } \\
\text { biological } \\
\text { stimulus }\end{array}$ & $\begin{array}{l}\text { Strategies developed for trigged drug release of liposome contents in response } \\
\text { to specific external stimuli, such as variations in magnetic field, temperature, } \\
\text { ultrasound intensity, light or electric pulses, and others. }\end{array}$ & $66-68$ \\
\hline
\end{tabular}

Theranostic

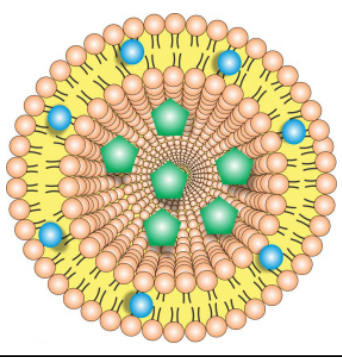

To increase liposomal drug accumulation into the brain, the use of ligandtargeted liposomes toward the receptors expressed on brain endothelial cells has been suggested, resulting in receptor-mediated transcytosis. One or more targeting ligands, such as antibodies and aptamers, can be covalently \begin{tabular}{ll} 
Strategies to permeate the BBB & Short description \\
\hline Cationization of the vector &
\end{tabular} Targeting ligand 
across the $\mathrm{BBB}$. In one example, one or more drug molecules could be reversibly bound to the surface of iron oxide nanoparticles, and when encapsulated within the core of liposomes, bypassed an established in vitro model of the BBB by action of an external magnetic field. ${ }^{67}$ Furthermore, it has been shown that magnetic liposomes can also be taken up into human monocytes, followed by the entry of nonmagnetic monocytes into the brain. ${ }^{67}$ Although this approach has not been largely explored for brain delivery, this may become a good strategy for effective drug delivery by stimuli-responsive liposomes.

Furthermore, multifunctional liposomes can be engineered into a single structure, providing a powerful approach to improve disease-specific detection, treatment, and follow-up monitoring. ${ }^{30}$ The term "theranostic" is used for nanoparticles that incorporate both therapeutic and diagnostic agents onto the same system. ${ }^{75}$ One example of theranostic agent for brain delivery was described by Wen et al, ${ }^{76}$ using quantum dots and apomorphine liposomally encapsulated for both brain therapy and imaging. The results showed that theranostic liposomes were transported across the BBB, providing a new and exciting strategy for brain-cancer imaging and therapy. ${ }^{76}$

It is worth mentioning that various routes of administration have been tested to access the brain for therapeutic purposes. For the delivery of liposomes to the CNS, intravenous injection seems to be the preferred route. The possibility of choosing between alternative routes of administration (oral, ocular, or mucosal) has been largely explored for bypassing the BBB, but it is beyond the scope of this article. For example, intranasal administration provides a practical and noninvasive approach to deliver drugs to the brain, allowing in this way an increase in the amount of drugs delivered across the barrier. ${ }^{77-79}$ It was shown that a liposomal formulation of rivastigmine was able to prevent degradation of the drug in the nasal cavity and to carry it through the mucosal barriers. ${ }^{80}$ Furthermore, the ability of cationic liposomes to delivering proteins to the brain via the intranasal route has also been demonstrated. ${ }^{81}$

In this review, a search of the literature was undertaken to investigate whether the use of liposomes offered any additional benefit than the therapeutic drug alone to treat most significant neurological diseases, such as Alzheimer's disease (AD), Parkinson's disease (PD), Huntington's disease, stroke, and brain cancer, and discuss its advantages and limitations. As a vast majority of CNS drugs have limited brain uptake, they may benefit from the use of liposomes as a drug-delivery vehicle into the brain. Moreover, liposomes have been widely explored as drug-delivery carriers to increase uptake of such drugs into the CNS. Therefore, there appears to be an obvious need for establishing CNS-penetrant and specific therapeutics to overcome the $\mathrm{BBB}$ and to do this in a controlled manner.

\section{Materials and methods Search strategy}

A PubMed and Web of Science search was conducted to identify all known published articles on liposomes in drug development focused on the treatment of neurological disorders up to May 2016.

\section{Study selection}

Initially, articles were identified using a combination of the following keywords: 1) "liposomes" and "Alzheimer"; 2) "liposomes" and "Parkinson"; 3) "liposomes" and "Huntington"; 4) "liposomes" and "stroke" or "cerebral ischemia"; and 5) "liposomes" and "glioma". Reviews, patents, editorial materials, book chapters, conference publications, and articles not published in English were excluded from the literature search. Based on titles/abstracts, only studies that described in vivo experiments were selected for review. The final decision to include/exclude studies was based on full copies of articles.

\section{Data extraction}

In vivo studies with liposomes have been performed in most species, including mice, rats, dogs, monkeys, and humans. As in vivo study interpretation of results deserves attention, especially because of the biological differences between species, this was the parameter used to group the studies. Also, the following parameters of the liposome formulation were compared: 1) route of administration, 2) time points, 3) liposome composition, 4) ligands, 5) drug or imaging agent, and 6) particle size. Lately, biological outcome into the CNS has also been reported.

\section{Results and discussion Neurodegenerative disorders}

$\mathrm{AD}, \mathrm{PD}$, and Huntington's disease were grouped together in this topic, because a growing number of studies indicates that these disorders share in common some features, such as the accumulation of intracellular or extracellular protein aggregates, selective degeneration of neurons, inclusion-body formation, and inflammation in particular brain regions. ${ }^{82}$ However, the search for reports on the use of liposomes for delivery of active or imaging compounds against neurological diseases was done individually. A flowchart of the literature search is shown in Figure 3. An initial search yielded a total 


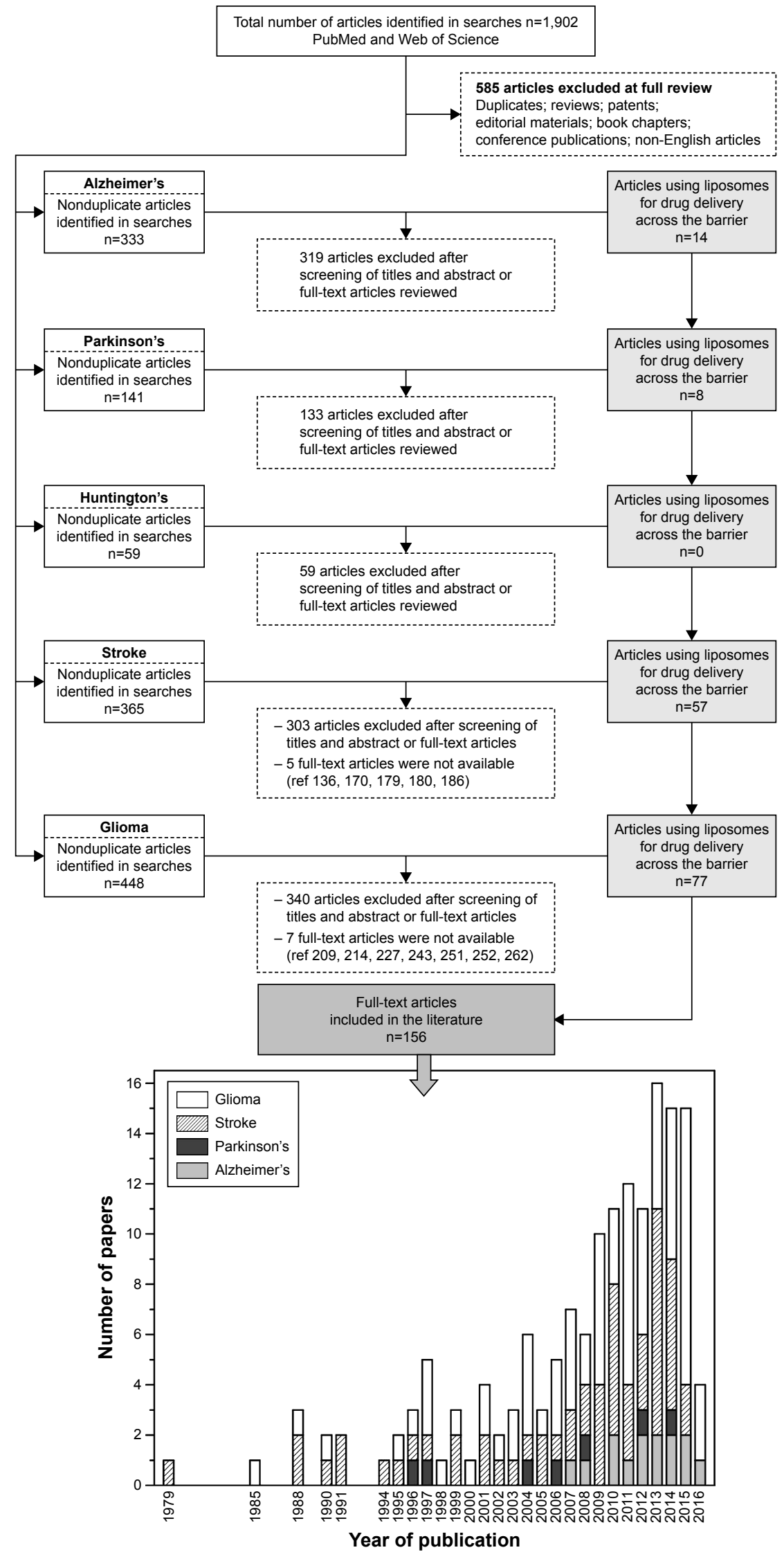

Figure 3 Flow diagram of studies that were identified based on the search terms described in the body of this article. Abbreviation: ref, reference. 
of 319 articles for AD, 141 articles for PD, and 59 articles for Huntington's, after excluding duplicate articles found in the PubMed and Web of Science databases. For AD, 26 full-text article reviews were performed, and 12 studies were included for their fulfillment of inclusion criteria (Figure 3, Table 3) ${ }^{80,83-95}$ For PD, 19 full-text articles were reviewed, and eight articles had all the requisites to be considered here (Figure 3, Table 3). ${ }^{96-103}$ Unfortunately, for Huntington's disease, just one full article was analyzed and this article did not show any outcome of interest for this disease, and for this reason was not included here (Figure 3).

\section{Liposomes in the treatment of Alzheimer's disease}

$\mathrm{AD}$ is a progressive and irreversible disease of the brain, affecting mainly people aged over 65 years. The neuropathogenesis of $\mathrm{AD}$ is a critical unsolved question. Progressive production and accumulation of insoluble protein aggregates, such as neurofibrillary tangles of hyperphosphorylated tau and amyloid- $\beta$ (A $\beta$ ) plaques are thought to underlie the neuropathology of $\mathrm{AD}$, leading to brain atrophy and neurodegeneration. ${ }^{104}$ In addition, some studies have also suggested that deficits in cholinergic neurotransmitter systems and increased levels of free radicals or proinflammatory cytokines might be involved in AD neuropathogenesis. ${ }^{105-108}$ More recently, a new potential cause for AD has been found in the behavior of certain immune cells that normally protect the brain instead beginning to consume a vital nutrient: the amino acid arginine. ${ }^{109}$ This new discovery has implications not only in a new potential cause of the disease but also as a new strategy for targeting disease.

To date, the US Food and Drug Administration (FDA) has approved three acetylcholinesterase inhibitors - rivastigmine, galantamine, and donepezil - for the treatment of AD, which lead to an increase in central cholinergic action in the brain areas affected by the disease. ${ }^{110}$ However, the administration of these inhibitors is associated with some severe side effects. It would thus be desirable to develop new formulations to avoid these side effects, and all studies proved that the use of liposomes was a good strategy in the treatment of AD. ${ }^{80,86,90-92,111}$ Intranasal delivery of rivastigmine or galantamine liposomes has been shown to be a viable and effective route to improve drug bioavailability for brain drug targeting. ${ }^{80,90,92}$ Intranasal delivery was also used as a successful approach for delivery of liposomes containing quercetin, which has antioxidant properties. As oxidative stress plays a very important role in the neuropathogenesis of AD, the use of quercetin liposomes has been shown to decrease neuronal oxidative stress. ${ }^{93-95}$
Moreover, there have been several studies exploring different strategies to block the effects of $A \beta$ and tau proteins that constitute major hallmarks of $\mathrm{AD} .^{84-87,91}$ Once encapsulated into liposomes, the $\mathrm{H} 102$ peptide, a $\beta$-sheet breaker, was able to block the early steps of aggregation and misfolding of the soluble $A \beta$, improving the spatial memory impairment of $A D$ in rats. ${ }^{112} \alpha$-Mangostin is a polyphenolic xanthone that exhibits pharmacological effects, such as anti-inflammation, antioxidant, and antitumor effects. When administered intravenously, $\alpha$-mangostin liposomes have been shown to protect and improve the neurons against $\mathrm{A} \beta$-oligomer toxicity in rats. ${ }^{88}$

Methoxy-XO4, a highly specific $\mathrm{A} \beta$ plaque ligand with the dual role of targeting moiety and fluorescent marker, has been conjugated to liposomes. When administered intravenously, these liposomes were able to cross the BBB in vivo and specifically bind to $A \beta$-plaque deposits, labeling vascular and parenchymal amyloid deposits in brain tissue. ${ }^{87}$ For example, glutathione PEGylated liposomes demonstrated efficient encapsulation of an antiamyloid single-domain antibody fragment $\left(\mathrm{V}_{\mathrm{H}} \mathrm{H}-\mathrm{pa} 2 \mathrm{H}\right)$, increasing its transport from blood into the brain. ${ }^{83}$ It has also been demonstrated that bifunctionalized liposomes decorated with phosphatidic acid and a modified ApoE-derived peptide are able to cross the $\mathrm{BBB}$ in vivo and destabilize $\mathrm{A} \beta$ aggregates, suggesting that this approach is a good option for AD treatment. ${ }^{84,85}$

Although the scope of this review is on liposome-strategies with the aim of facilitating $\mathrm{BBB}$ crossing, it is important to mention that other strategies have been developed for the use of liposomes for AD treatment. ${ }^{89,113-116}$ Curcumin is a natural compound extract from the plant Curcuma longa, and has been reported to be a fluorescent molecule with high affinity for the $A \beta$ peptide and able to reduce $A \beta$ aggregation. In this way, intracranial injection of liposomes encapsulating curcumin efficiently labeled $\mathrm{A} \beta$ deposits in both human and mice tissues, proving to be an effective formulation for diagnosis and treatment of AD. ${ }^{113}$ Also, intraperitoneal injection of liposomes containing phosphatidic acid or cardiolipin was able to reduce $A \beta$ peptides in the plasma and shifted the equilibrium that exists between brain and blood $A \beta$ peptides, slightly affecting the plaques in the brain. ${ }^{89}$ Lastly, different liposome-based vaccines were developed and directed toward $\mathrm{A} \beta$ plaques ${ }^{115,116}$ and tau. ${ }^{114}$

\section{Liposomes in the treatment of Parkinson's disease}

PD affects 4 million people worldwide. ${ }^{117}$ The neuropathogenesis of PD is characterized by motor symptoms, such as tremor, rigidity, slowness of movement, difficulty with walking, and problems with gait. These motor symptoms result primarily 


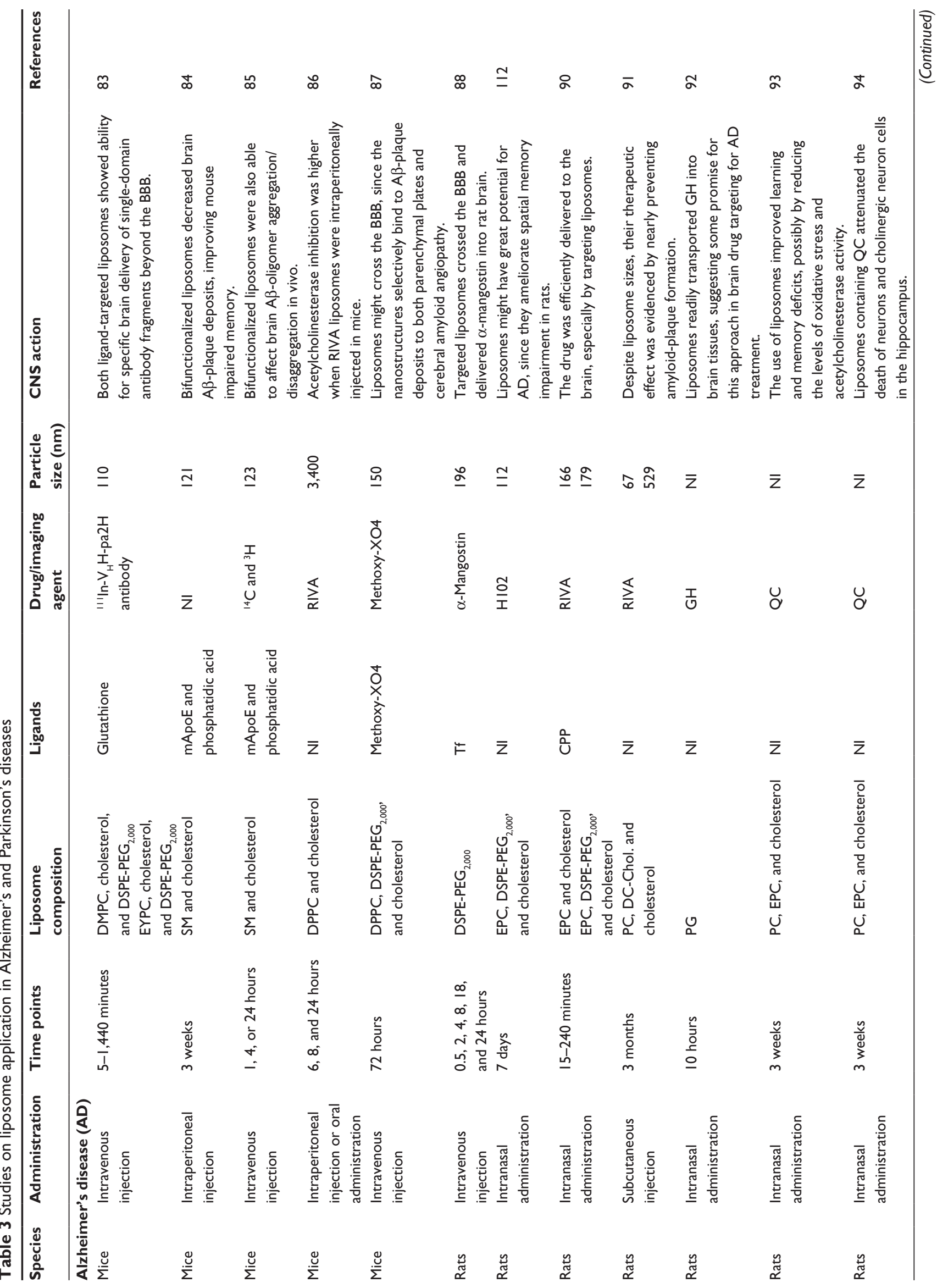




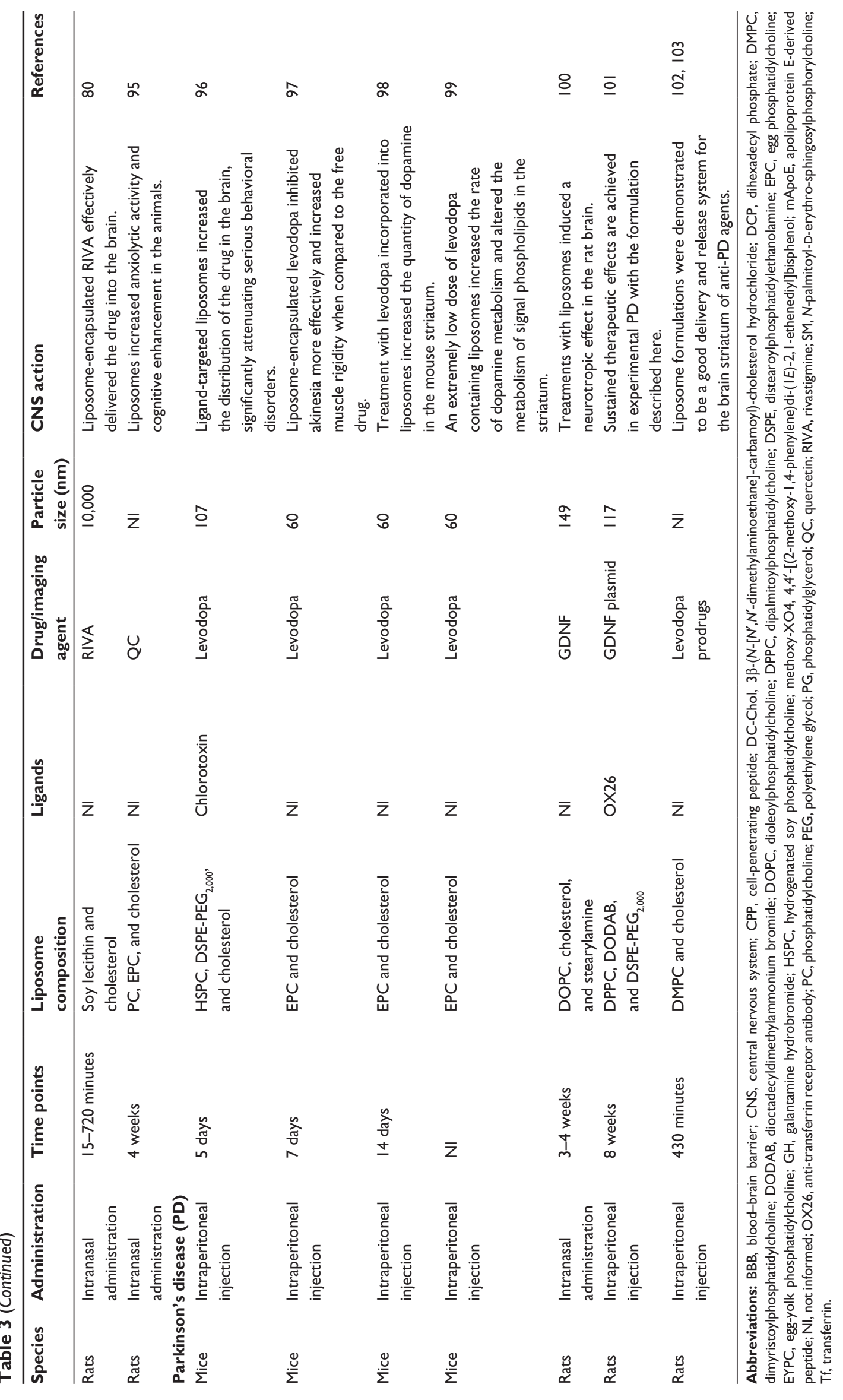


from the death of dopamine-generating neurons in an area of the brain called the substantia nigra, leading to the decreasing of dopamine levels. ${ }^{118}$ Also, misfolding and intracellular aggregation of $\alpha$-synuclein fibrils, also known as Lewy bodies, are pivotal to PD neuropathogenesis. ${ }^{117,118}$ Mitochondrial dysfunction and oxidative stress may also be implicated in PD neurodegeneration. ${ }^{118}$ However, the mechanisms underlying PD pathogenesis have not been fully elucidated.

Currently, available therapies for PD are essentially symptom-directed, having no effect on the disease progression. To date, the natural precursor of dopamine, levodopa or L-dopa, has been used in the clinic for several years. ${ }^{119}$ However, levodopa cannot be administered alone, since it is converted to dopamine via peripheral dopaminedecarboxylase enzyme and causes such side effects as sleepiness, nausea, and dyskinesia. ${ }^{120}$ A recently reported study overcame this problem, developing liposomes for site-specific delivery of levodopa into the CNS. ${ }^{96}$ Chlorotoxin-modified stealth liposomes encapsulating levodopa proved to be an efficient nanocarrier, increasing levodopa concentration into the substantia nigra and striatum. ${ }^{96}$ In the same way, it was also observed that intraperitoneal injection of liposome formulations encapsulating anti-PD drugs could improve the release of dopamine in the striatum region. ${ }^{96-99,102,103}$

Also, there are ongoing studies showing that GDNF is able to promote growth, regeneration, and survival of substantia nigra dopamine neurons, preventing the progression of PD if administered in the early stages of the disease. ${ }^{121-124}$ Recently, a very promising study showed neurotrophic and neuroprotective effects of GDNF protein into the rat brain. ${ }^{100}$ Although the liposomal preparation of GDNF offered no significant advantage of GDNF alone after intranasal injection, the liposomal formulation might have a protective effect on the protein, preventing it from degradation. ${ }^{100}$ Another example that demonstrated the improvement of the treatment of the disease with GDNF is reported in Xia et al. ${ }^{101}$ In this study, intravenous administration of OX26-targeted PEGylated liposomes was used as a nonviral gene-delivery system to deliver GDNF plasmid into the CNS. The expression of GDNF genes, under the influence of a rat tyrosine hydroxylase promoter, was observed in organs where the $\mathrm{TH}$ gene is highly expressed, including the substantia nigra, adrenal gland, and liver. Sustained therapeutic delivery was achieved at the neurons of the nigrostriatal tract in experimental PD. ${ }^{101}$ Lastly, novel liposomal formulations have been characterized and efficacy in PD rats reported after intracerebral injection. ${ }^{125-130}$ As the injection was at the local site of the disease and did not show any evidence of transposing the $\mathrm{BBB}$, they were not considered in this review article.

\section{Stroke or cerebral ischemia}

Unlike the other neurological disorders described so far, stroke has high incidence, disability, and mortality rates in a modern society. ${ }^{131}$ An ischemic stroke is characterized by the sudden reduction of brain blood flow due to obstruction of cerebral vasculature, damaging the neural tissue (ischemic penumbra zone). ${ }^{132}$ Unfortunately, the treatment for stroke has its limitations, due to the poor ability to deliver therapeutic agents across the BBB. Therefore, efforts have been made to identify and develop drug-delivery systems to the brain. Liposomes are described as a possible valuable system to achieve better therapeutic effects in the treatment of stroke. The search for reports on the use of liposomes as drug-delivery nanocarriers for the treatment and/or diagnosis of stroke is shown in Figure 3. An initial search yielded a total of 365 articles after excluding duplicate articles found in the PubMed and Web of Science databases. In total, 62 articles were eligible. ${ }^{133-194}$ Although all articles described new nanocarriers for the delivery of therapeutic molecules into the brain, only 57 studies are included in Table 4, because the full text of five articles ${ }^{139,173,182,183,189}$ was not available to access.

The initial treatment for acute ischemic stroke consists in the administration of the FDA-approved tissue plasminogen activator (tPA), which is effective within the first 3 hours after the event occurs. This drug works on quickly dissolving the blood clot to restore brain perfusion. ${ }^{195}$ However, its use is limited, due to elevated risk of cerebral hemorrhage, most probably due to the generation of free radicals posttreatment. ${ }^{196}$ Because oxidative damage is an important aspect of the pathology of stroke and involved in vascular cell-membrane damage, researchers considered the possibility of developing a novel system to deliver tPA efficiently to the ischemic penumbra area in the brain. Actin is already known to be able to bind to antigens present at the surface of cells with damaged membranes. Therefore, actin-targeted liposomes for tPA delivery were developed, and this new drug-delivery system was in fact very efficient in delivering tPA within the brain, reducing hemorrhagic transformation in rats after focal embolic stroke. ${ }^{173}$ Furthermore, the enzyme SOD was demonstrated to be an excellent biological natural free radical scavenger, and its ability as a neuroprotectant agent was tested. As free enzymes possess no BBB-penetration 


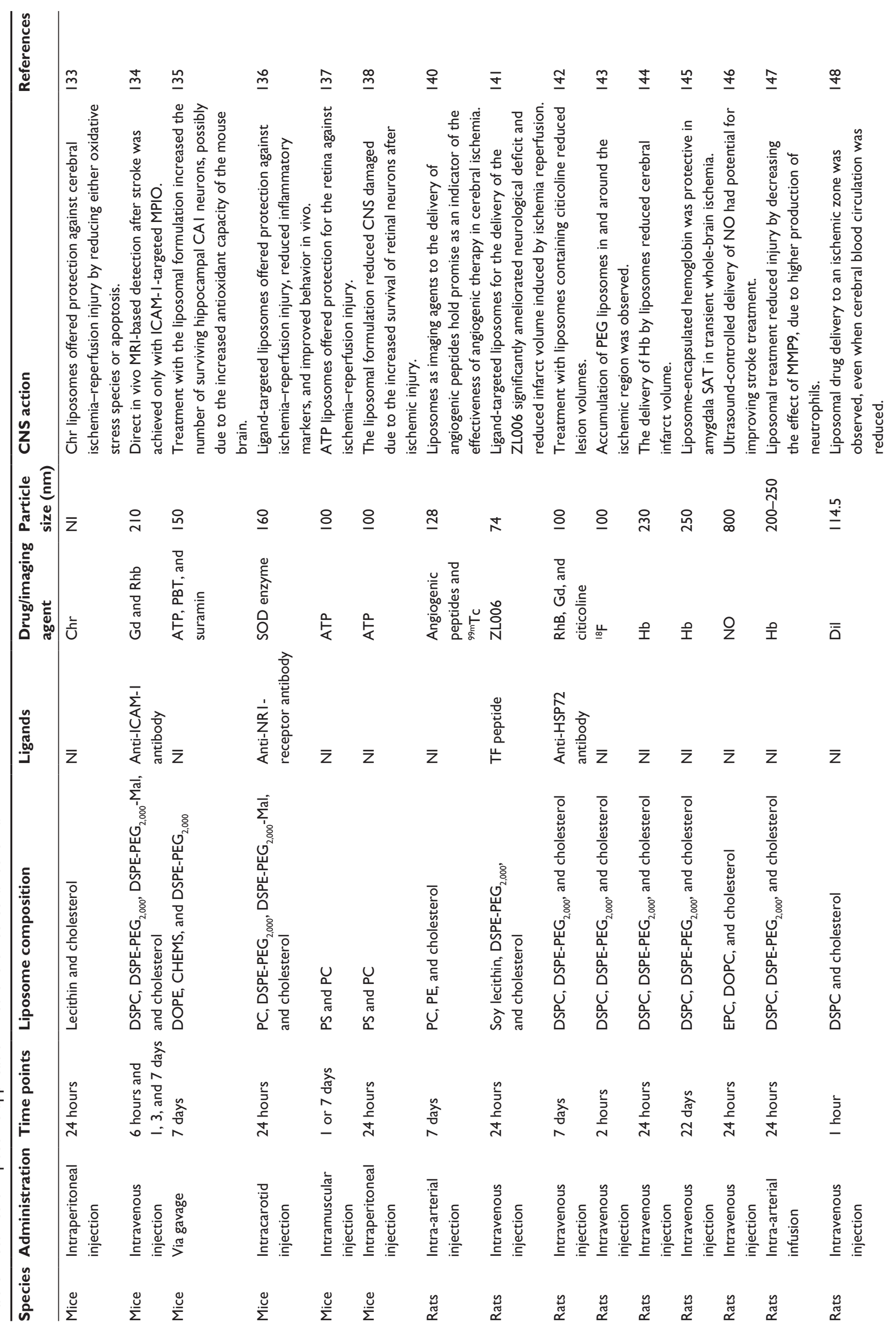




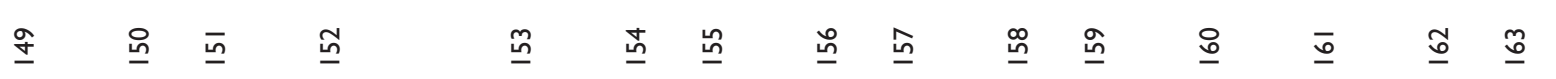

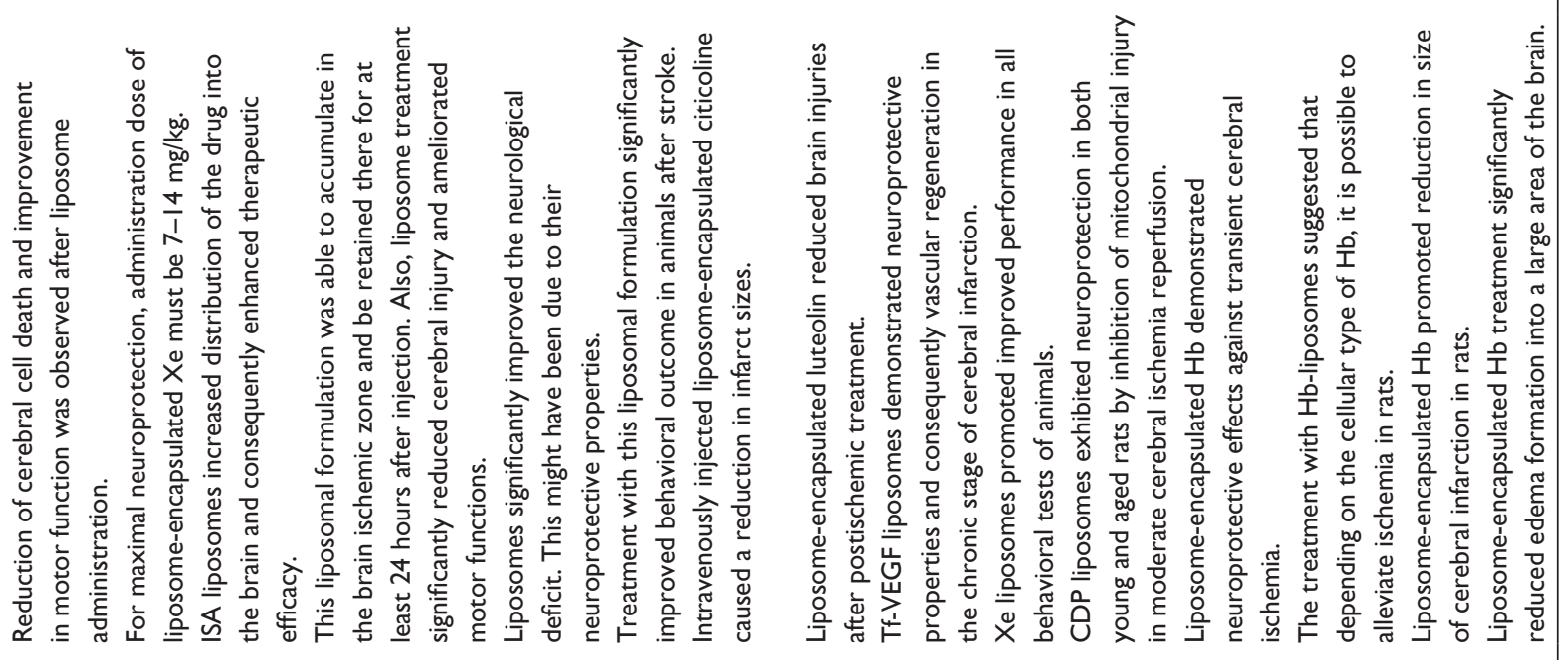

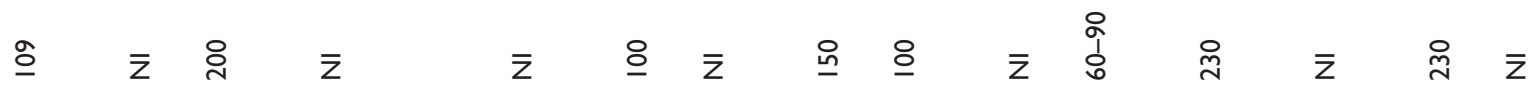

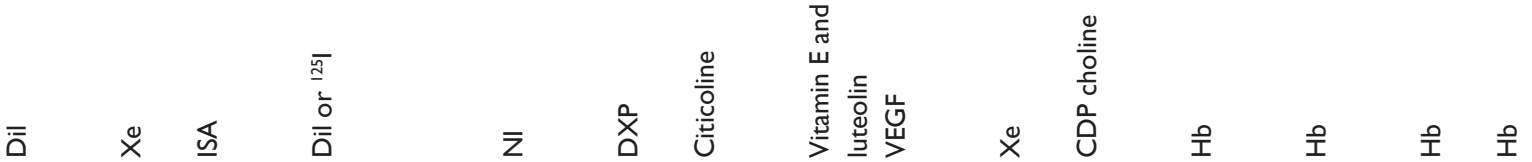

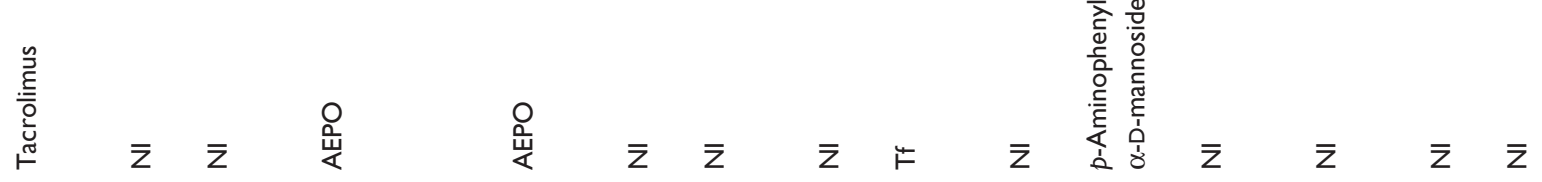

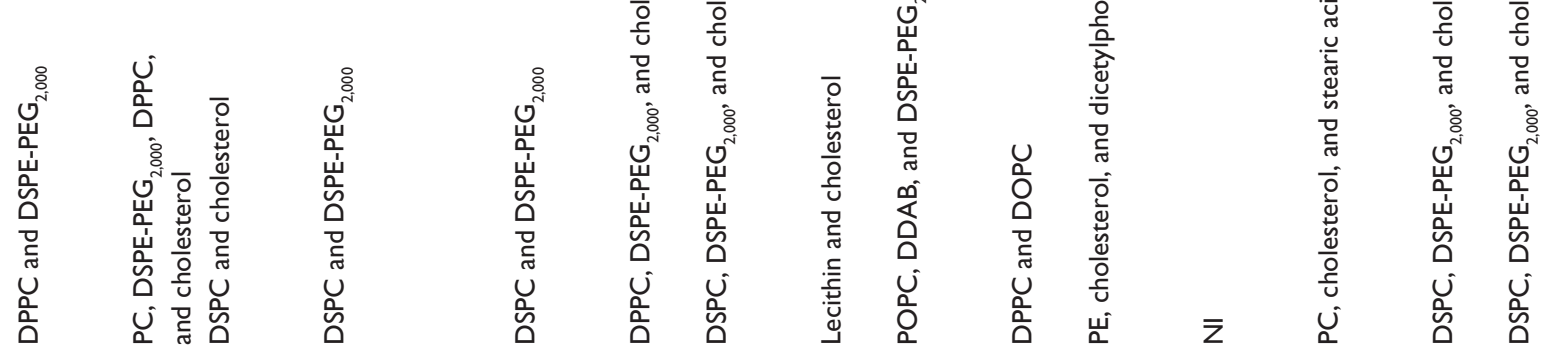

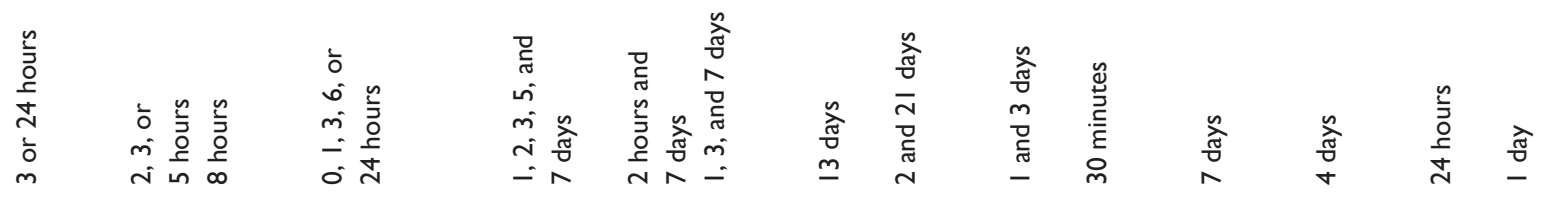

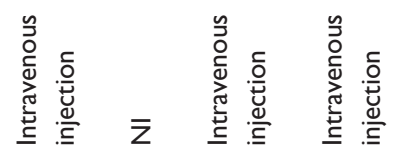

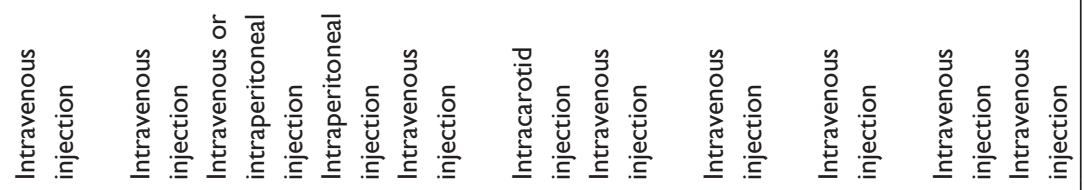

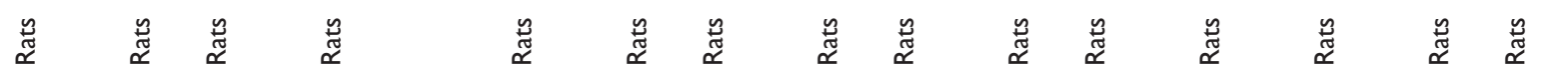




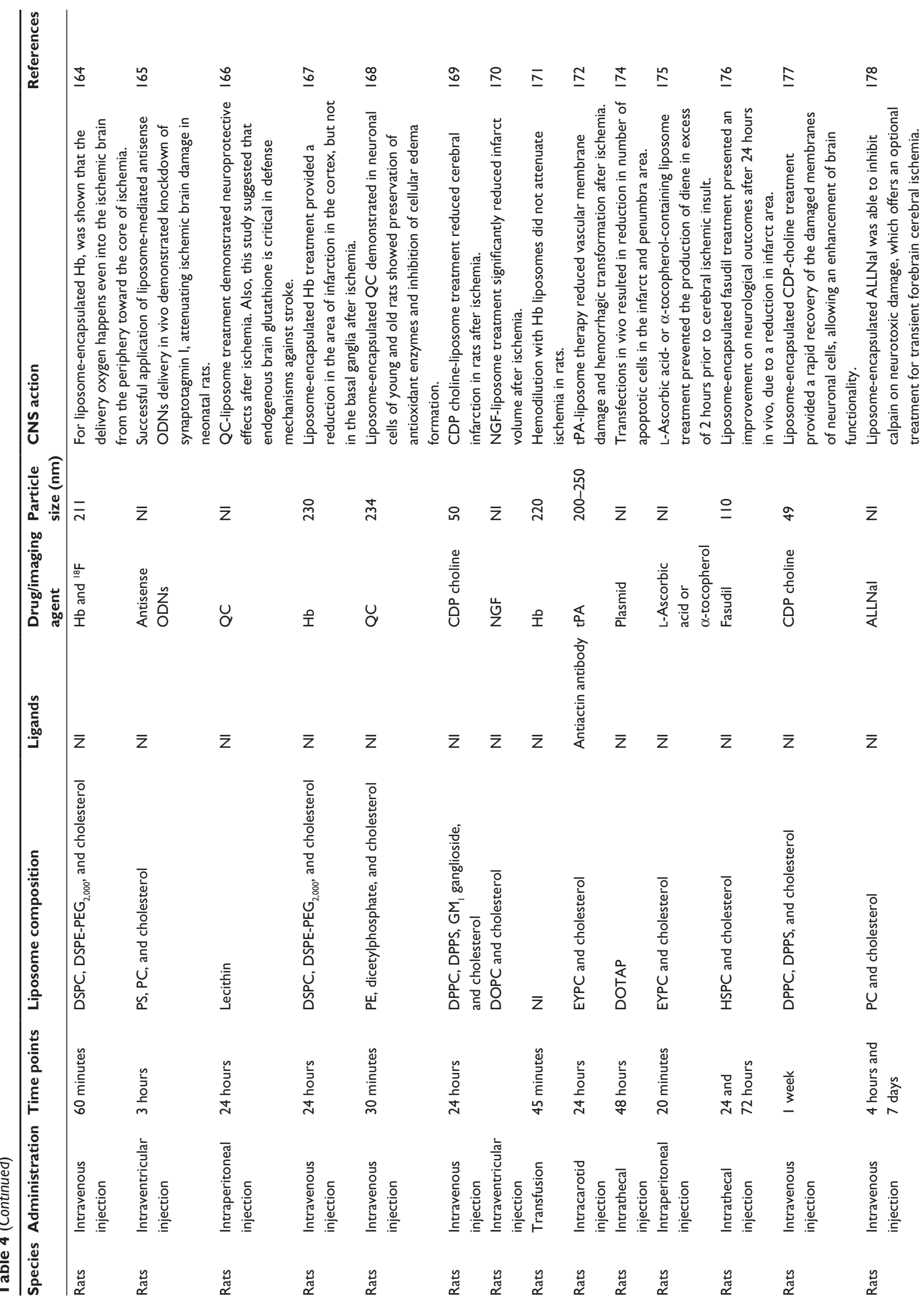




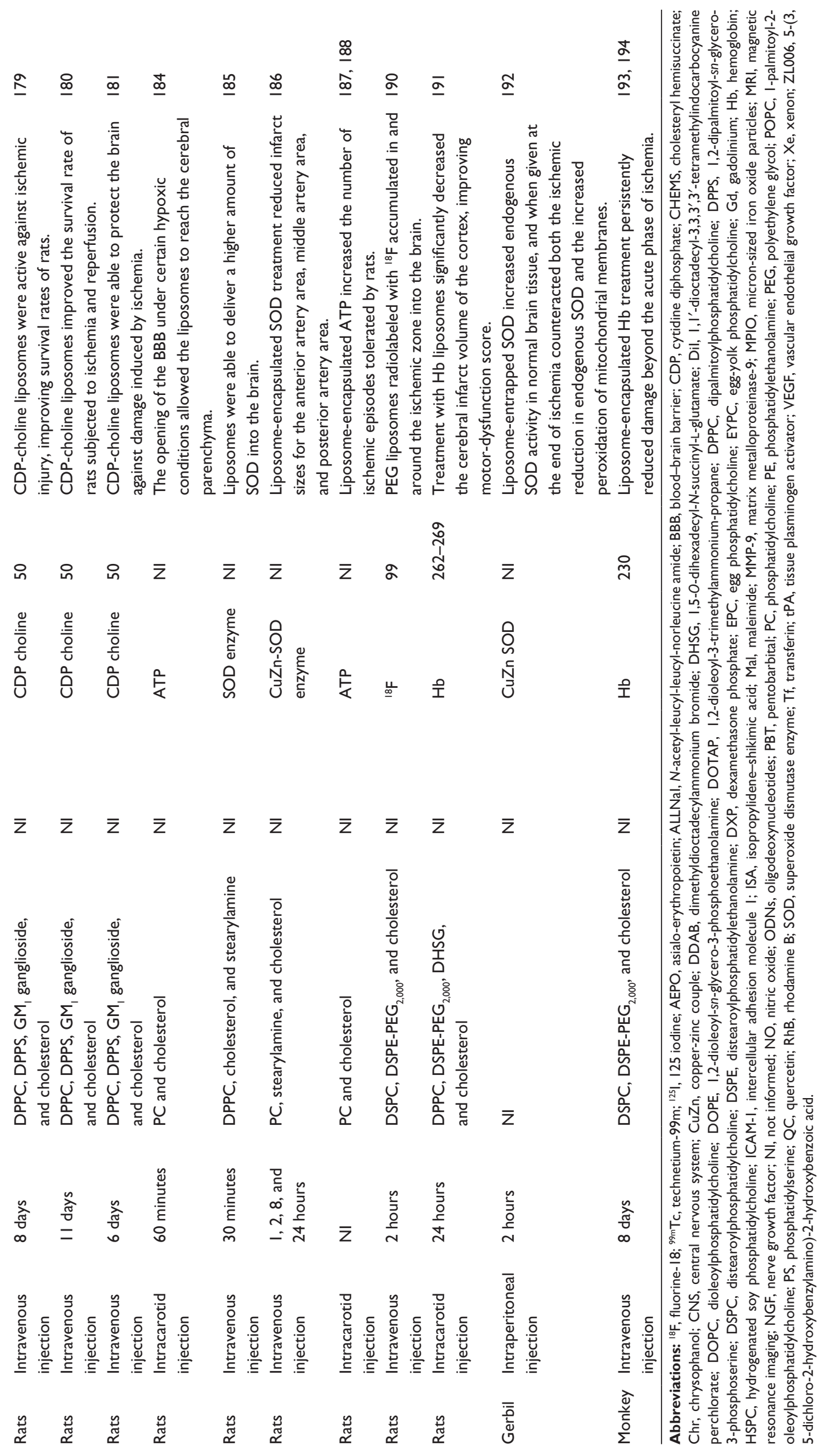


capacity and degrade rapidly in the serum, SOD encapsulation in liposomes was needed. In vivo experiments demonstrated the efficacy of SOD-loading liposomes to get into the brain, providing significant protection against free radicals. ${ }^{136,139,185,186,189,192}$

Moreover, a wide debate is ongoing in the literature about new strategies to treat this disease. Neuroprotective and neuroreparative drugs (for example, citicoline) are under development. ${ }^{197}$ Citicoline, an exogenous form of cytidine5 -diphosphocholine, is a key intermediate in the biosynthesis of phosphatidylcholine, the primary neuronal membrane phospholipid that is degraded during brain ischemia to free radicals and fatty acids. In addition, citicoline restored $\mathrm{Na}^{+} / \mathrm{K}^{+}$ ATPase, inhibited activation of phospholipase $\mathrm{A}_{2}$, and accelerated cerebral edema reabsorption. ${ }^{198}$ Therefore, citicoline was considered a good candidate for molecular therapy for stroke, since its acts at several points on the ischemic pathway. Unfortunately, due to the drug's polar nature, crossing the BBB was far lower than desired. It has been observed that liposomeencapsulated citicoline increases its bioavailability within the brain parenchyma and improves its therapeutic efficacy for the treatment of stroke in animals. ${ }^{142,155,159,169,177,179-182}$

Besides damaged blood vessels in cerebral ischemia, another important process that occurs in stroke is neovascularization or angiogenesis. This is the physiological process of forming new blood vessels from the existing vasculature in healthy brain tissue into areas of ischemic penumbra. ${ }^{199}$ The outermost cells in the zone of ischemic penumbra slightly restore their metabolism activities, since they have more blood supply when compared to cells more centrally located in the ischemic area. At this site, where blood supply is limited, there is rapid consumption of ATP, due to low levels of oxygen. Therefore, the delivery of exogenous ATP by liposomes could restore the metabolism of ischemic cells and reduce the area of injury. ${ }^{135,137,138,183,184,187,188}$

As mentioned earlier, cells within the infarcted area of ischemic tissue do not receive enough oxygen or nutrients to generate ATP. For this purpose, liposome-encapsulated hemoglobin $(\mathrm{Hb})$ was engineered as a pharmacological agent able to deliver oxygen for the treatment of ischemic diseases. Several studies reported in the literature suggest the efficacy of $\mathrm{Hb}$ liposomes in the treatment of stroke by enhancing the biodistribution of $\mathrm{Hb}$ liposomes within the ischemic area in the brain. ${ }^{144,145,147,160-164,167,171,191,193,194}$ In the same way, liposomes for the delivery of angiogenic peptides ${ }^{140}$ and $\mathrm{VEGF}^{157}$ to promote angiogenesis in ischemic tissue were developed, and both formulations effectively promoted vascular regeneration. ${ }^{140,157}$
Over the years, many liposomal formulations have been developed for the treatment of stroke. Moreover, when liposomes were associated with contrast agents, researchers observed that they quickly accumulated in the ischemic zone. ${ }^{134,143,148,152,190}$ Some formulations have demonstrated their ability to improve in vivo activity of drugs, such as chrysophanol, ${ }^{133}$ dexamethasone phosphate, ${ }^{154}$ nerve growth factor, ${ }^{170} \mathrm{Xe},{ }^{150,158} \mathrm{FK} 506,{ }^{149}$ isopropylidene-shikimic acid,,${ }^{151}$ asialo-erythropoietin, ${ }^{153}$ antisense oligonucleotides, ${ }^{165}$ plasmids, ${ }^{174}$ quercetin, ${ }^{166,168}$ fasudil, ${ }^{176}$ nitric oxide, ${ }^{146} \mathrm{~N}$-acetylleucyl-leucyl-norleucine amide, ${ }^{178}$ and a combination of synergistic drugs. ${ }^{156,175}$ Very recently, a promising uncoupling new drug - ZL006 (5-(3, 5-dichloro-2-hydroxybenzylamino)-2hydroxybenzoic acid) - was developed for stroke treatment. Its mechanism of action is based on the selective blocking of the coupling of nitric oxide synthase, and it was also recognized as a neuroprotective drug. As with many other drugs, ZL006 possesses low to BBB-permeability capacity. However, its encapsulation in immunoliposomes targeted the BBB and significantly enhanced the delivery of ZL006 within the brain. A remarkable neuroprotective effect was also observed. ${ }^{141}$

\section{Brain cancer - glioma}

There are more than 100 different types of brain and CNS tumors. In this article, we focused our search on the term "glioma", which encompasses all tumors that arise from glial cells, including astrocytomas, oligodendrogliomas, ependymomas, and glioblastomas multiforme. ${ }^{200}$ Glioblastoma multiforme is by far the most common and aggressive cancer form of the glial tumors. The current standard of care for this type of cancer includes surgery, followed by treatment with radiation and/or chemotherapeutic drugs. The current median overall survival of patients with glioblastoma multiforme is less than 15 months after surgery, followed by synergistic combination of radiotherapy and chemotherapy with the anticancer drug temozolomide. ${ }^{201}$ Treatment for this type of cancer has its limitations, due to the poor ability to deliver therapeutic agents across the two unique barriers present in the brain: the BBB and the blood-brain tumor barrier (BBTB). Moreover, the low accumulation of nanoparticles into brain tumors by the enhanced permeability and retention (EPR) effect should be also taken into account. ${ }^{202}$ Therefore, efforts have been made to identify and develop drug-delivery systems for the brain. Liposomes are described as a possible valuable system to achieve better therapeutic effects in the treatment of gliomas, since several targeting strategies have been reported showing ability to reach the brain and to target the tumor. The search for reports on the use of liposomes as 
drug-delivery nanocarriers for the treatment and/or diagnosis of gliomas is shown in Figure 3. An initial search yielded a total of 448 articles after exclusion of duplicate articles found in the PubMed and Web of Science databases. In total, 80 articles were eligible. ${ }^{60,64,65,203-283}$ Although all described new nanocarriers for the delivery of therapeutic molecules into the brain, only 77 studies are included in Table 5, because the full text of seven articles ${ }^{212,217,230,246,254,255,265}$ was not available to access.

\section{Design of liposomal drug-delivery systems for glioma diagnosis}

One of the most challenging problems in therapy of gliomas is their detection in the earliest stages of development. Like many tumor types, early detection correlates with successful therapy. Therefore, both new diagnostic and therapeutic approaches need to be developed for glioma-imaging oncology. For this purpose, a huge variety of contrast agents have been encapsulated into liposomes. These new nanomaterials may provide new opportunities for biomedical imaging, due to their unique magnetic, optical, and/or chemical properties, leading to the creation of better contrast-enhancement agents and increasing the sensitivity of techniques clinically available for diagnosis of brain tumors. ${ }^{284}$

Modern imaging techniques, such as magnetic resonance imaging (MRI), optical imaging, ultrasound, and single-photon-emission computed tomography (SPECT), are rapidly emerging as noninvasive modalities for detection and follow-up posttreatment of gliomas. ${ }^{285,286} \mathrm{MRI}$ is the preferred approach for glioma imaging, since it provides high-spatial-resolution anatomic images of this tumor type. ${ }^{287}$ Optical imaging applied to glioma therapy has the potential to localize and identify intrinsic brain tumors for removal during surgery. ${ }^{288}$ Ultrasound, unlike MRI, defines tumor volume and provides intraoperative localization of tumor tissue, although its use is limited by the presence of the skull. ${ }^{285}$ SPECT yields growth rate and gives information about the heterogeneity of gliomas, but provides low-spatial-resolution images. ${ }^{289}$ Positron-emission tomography (PET) provides functional information, since this technique is highly sensitive for measurements of biological processes, such as cell proliferation, angiogenesis, and glucose consumption. ${ }^{290}$

Paramagnetic contrast agents are the most widely used agents to enhance the visibility of gliomas in MRI images. Gadolinium (Gd)-based compounds, such as Gd-diethylenetriaminepentaacetic acid, gadodiamide, and gadoteridol, are effective contrast agents, owing to their seven unpaired electrons. Although Gd-based compounds are able to cross the BBB, a key advantage of using liposomes as Gd carriers is preferential localization at the tumor site through the EPR effect. In this way, it was shown that Gd liposomes with prolonged blood-circulation time tend to accumulate in the intratumoral extravascular space after moving across the tumor's leaky vasculature. ${ }^{208,254}$ Moreover, a recent advance was reported in the design of a $\mathrm{pH}$-responsive $\mathrm{Gd}$ liposome that was able to release the imaging agent into a cerebral glioma rodent model, detecting with $0.2 \mathrm{pH}$ precision the mildly acid tumor microenvironment. ${ }^{208}$

Methods for optical imaging of glioma are based on fluorescence. The lipid-binding fluorescent carbocyanine dyes DiD (4,4'-diisothiocyanatostilbene-2,2'-disulfonic acid, disodium salt), $\mathrm{DiO}$ (3,3'-dioctadecyloxacarbocyanine perchlorate), and DiI (1,1'-dioctadecyl-3,3,3,'3,'tetramethylinocarbocyanine perchlorate) are widely used for imaging studies. The characteristics of aqueous-insolubility ease of aggregate formation and the fact that these dyes do not readily cross the $\mathrm{BBB}$ suggest that it would be desirable to develop a liposome-based system. In this way, the carbocyanine dyes have been encapsulated into liposomes with the ability to demarcate tumors. ${ }^{60,256,269}$ The results of these studies suggest that those formulations, independent of the mode of administration, stained the tumor tissue and increased their bioavailability. ${ }^{60,256,269}$ However, the use of these fluorescent probes has the disadvantage of requiring low-light conditions for the visualization of tumors in vivo, which is not useful in a surgical environment. It was recently reported that Evans blue liposomally encapsulated was able to demarcate visually the margins of invasive gliomas, which may not significantly change the surgical conditions for the resection of this type of tumor. ${ }^{232}$

Also, studies reported in Table 5 suggest that the use of MRI or optical imaging alone in the imaging of gliomas is not enough for their classification and grading, optimal treatment, and follow-up after treatment, ${ }^{261,273}$ since each imaging technique is associated with individual advantages and limitations. Furthermore, it is generally observed that the presence of targeting ligands over the liposome surface improves the uptake of vesicles by target cancer cells and increases their retention time within tumors. ${ }^{231,233,239,247,253}$ In gliomas, angiogenesis seems to be the preferable target area for diagnosis of this cancer. Angiogenesis, the formation of new vessels, is a key process for glioma survival and growth. ${ }^{291}$ From the literature search, two molecules were identified for angiogenic cells: endoglin, also known as CD105, and the Ala-Pro-Arg-Pro-Gly peptide. MRI of endoglin-target liposomes was able to demonstrate tumor 


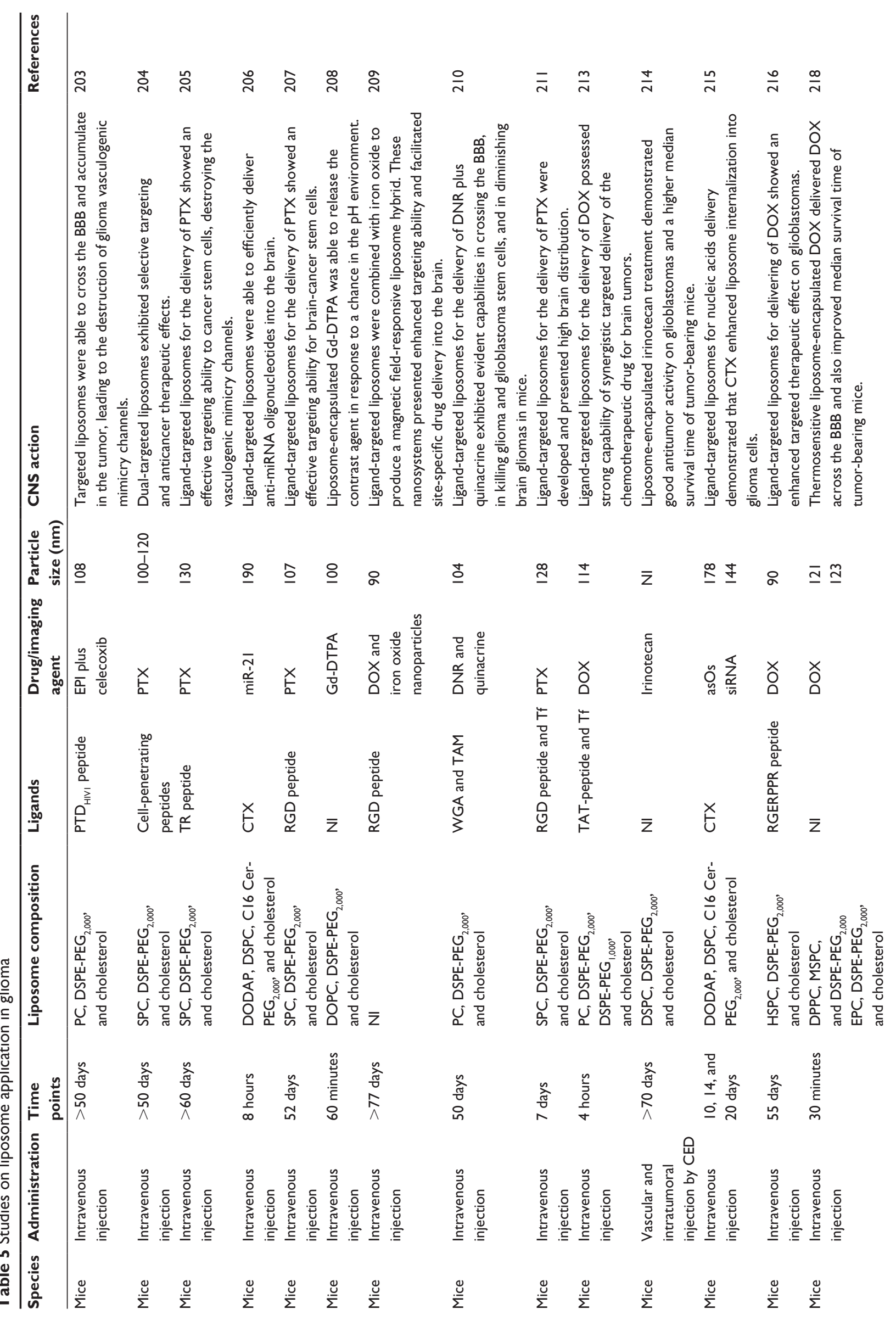




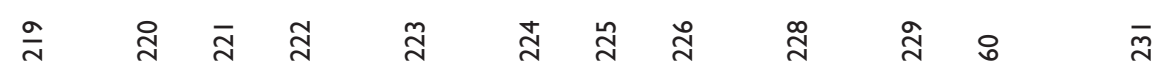
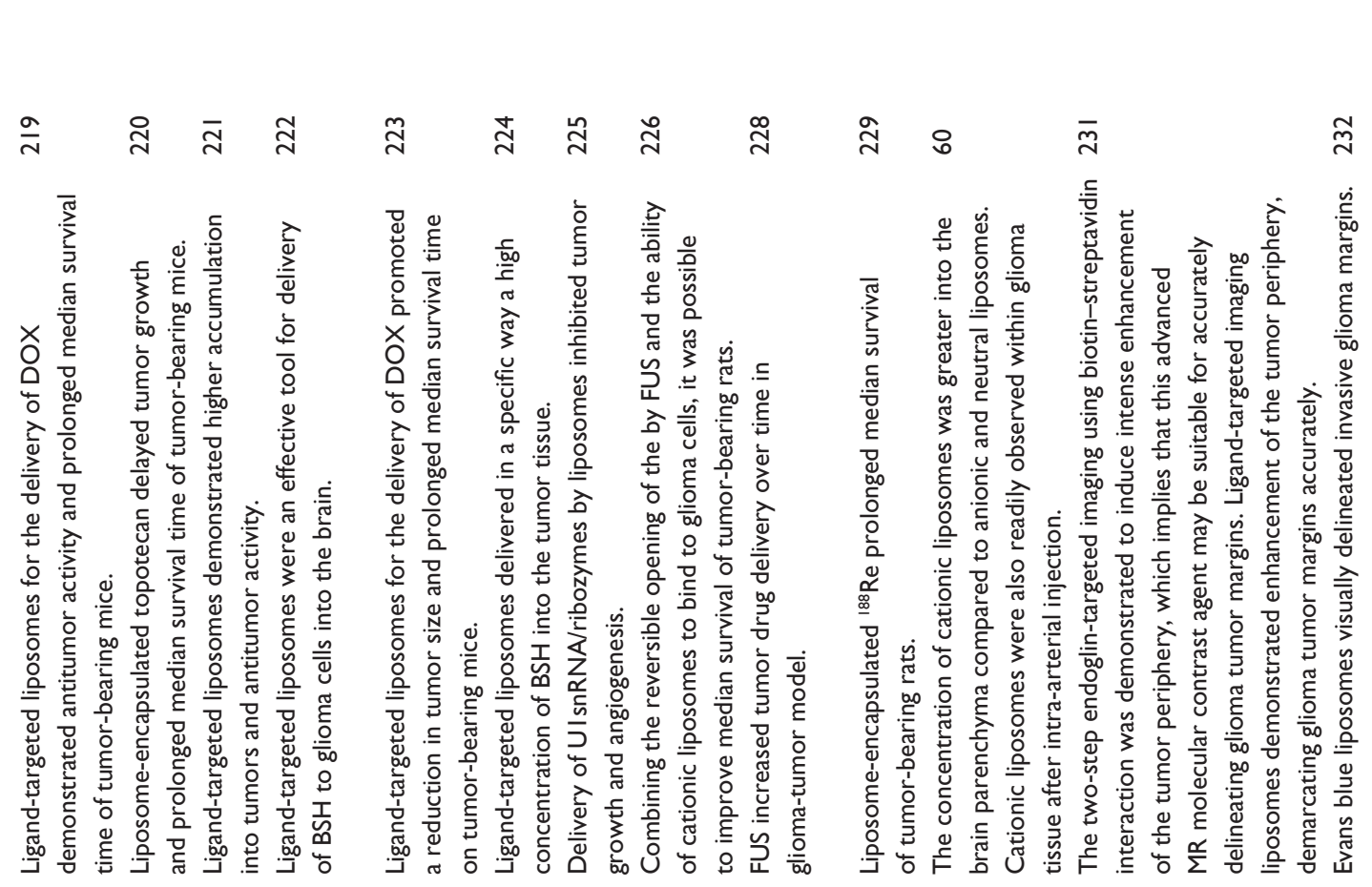

ָָ⿻

8

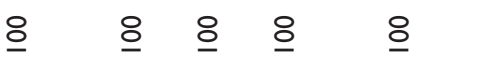

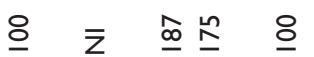

ळ $\bar{z} \bar{z} \bar{z}$ i

$\underline{\underline{0}} \&$

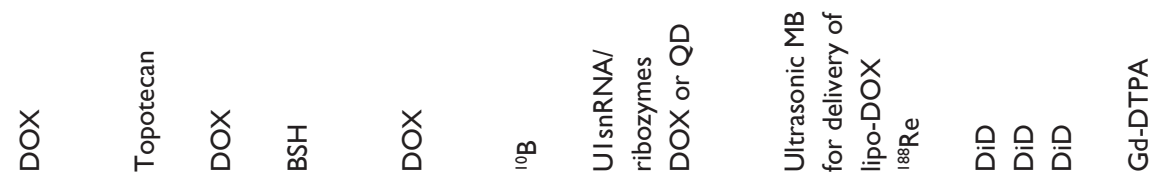

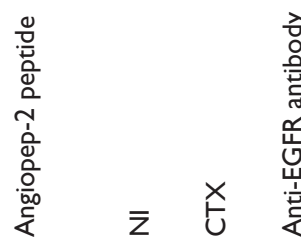

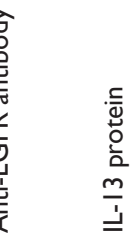

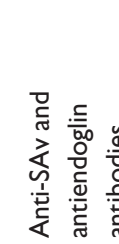

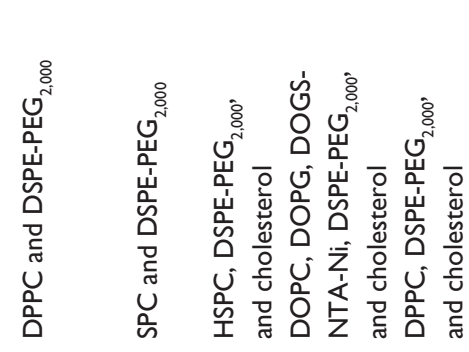

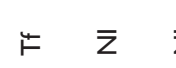

$\bar{z} \quad \bar{z} \quad \bar{z} \quad \bar{z} \bar{z} \bar{z}$

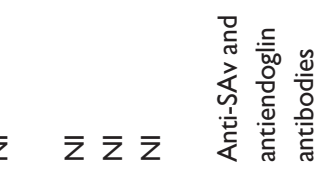

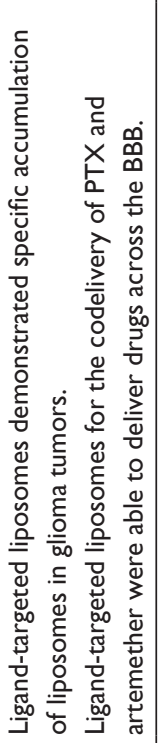

坴

n
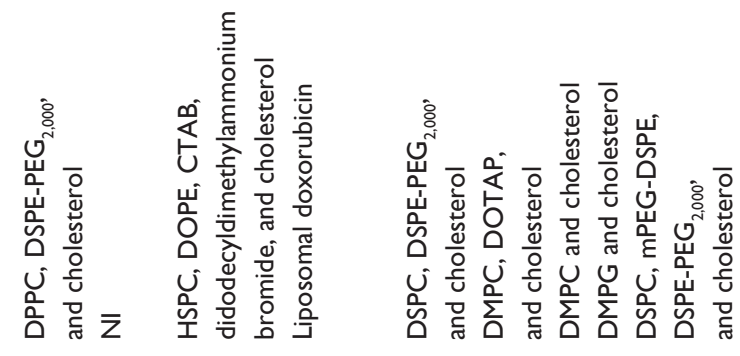

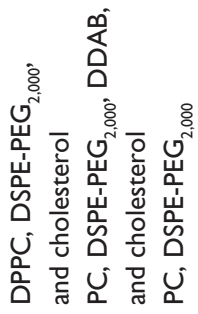

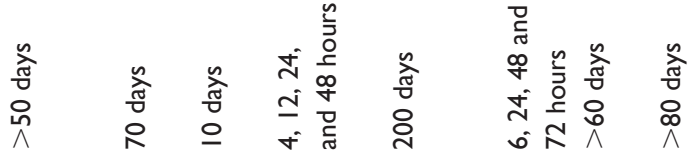

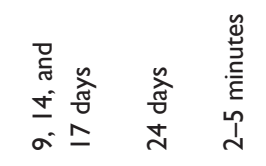

$\stackrel{\stackrel{n}{亏}}{\stackrel{0}{\frac{c}{+}}}$

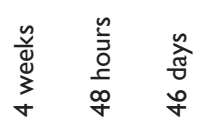

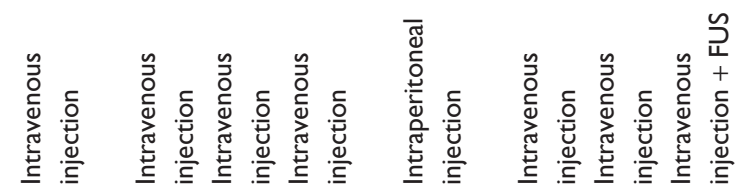
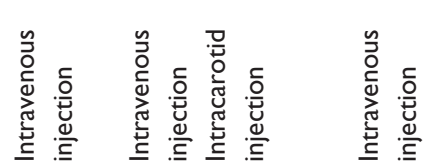

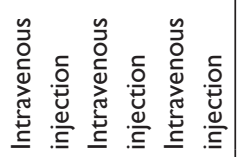

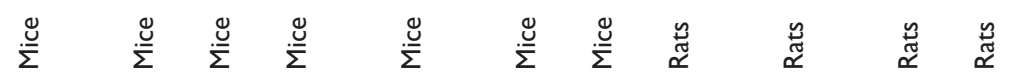

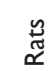

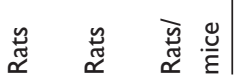




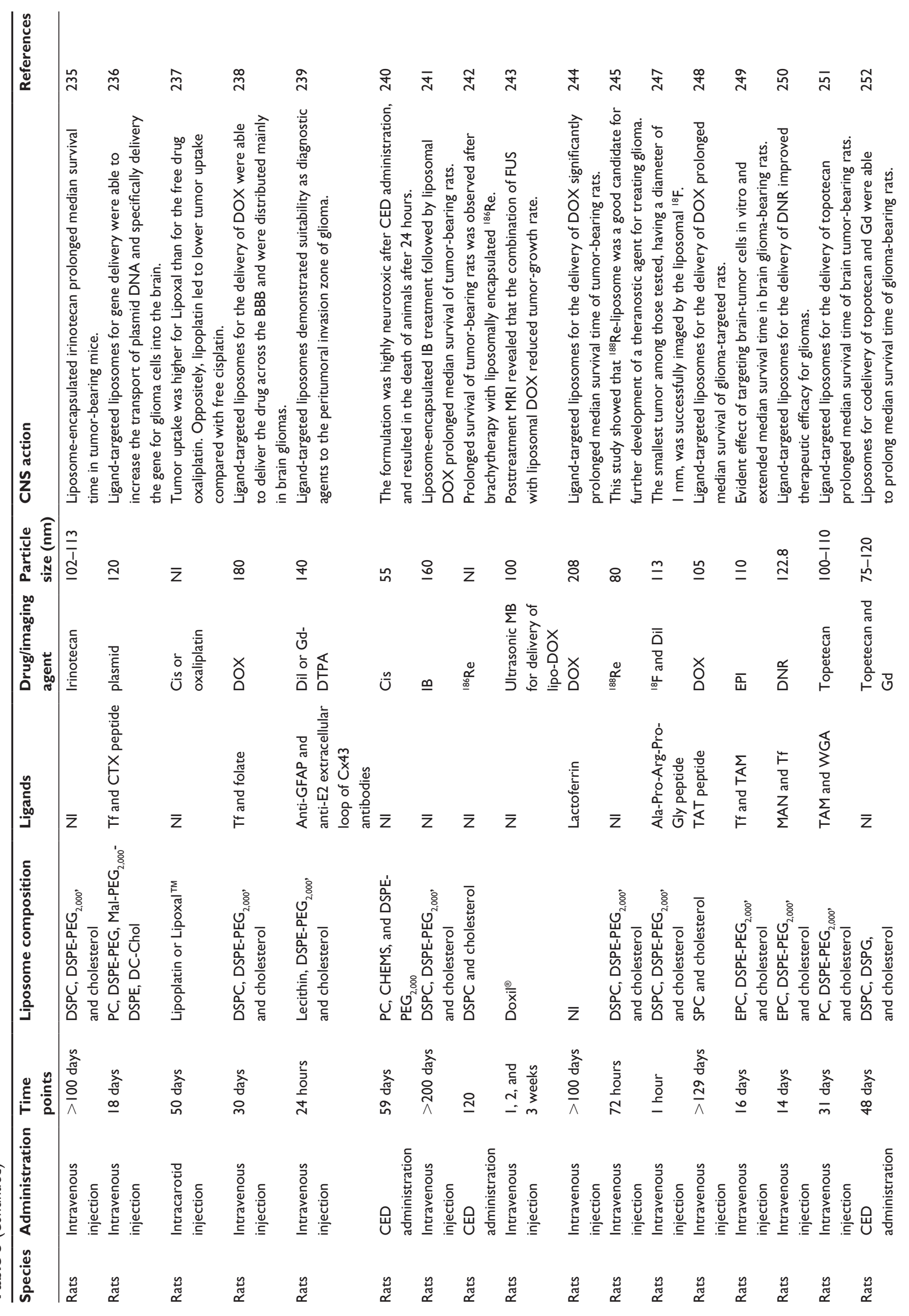




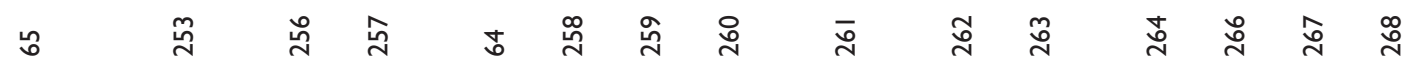
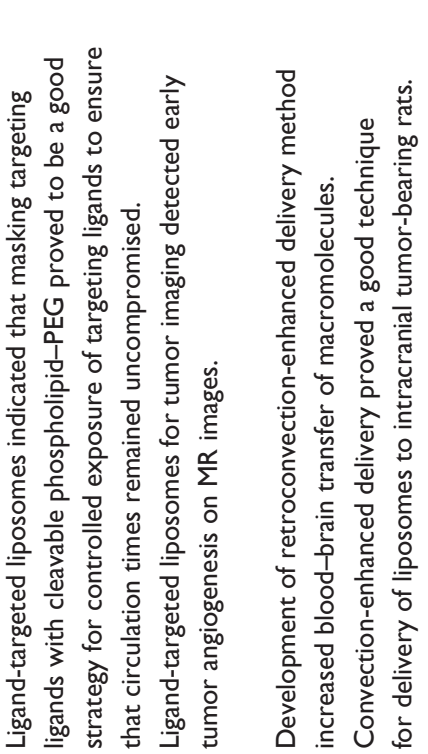

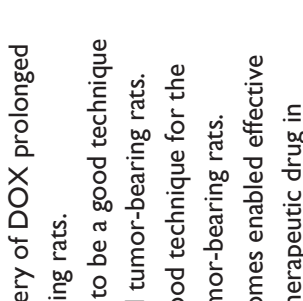

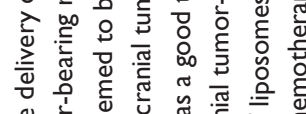

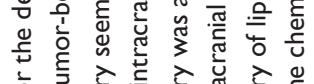

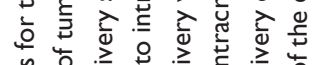

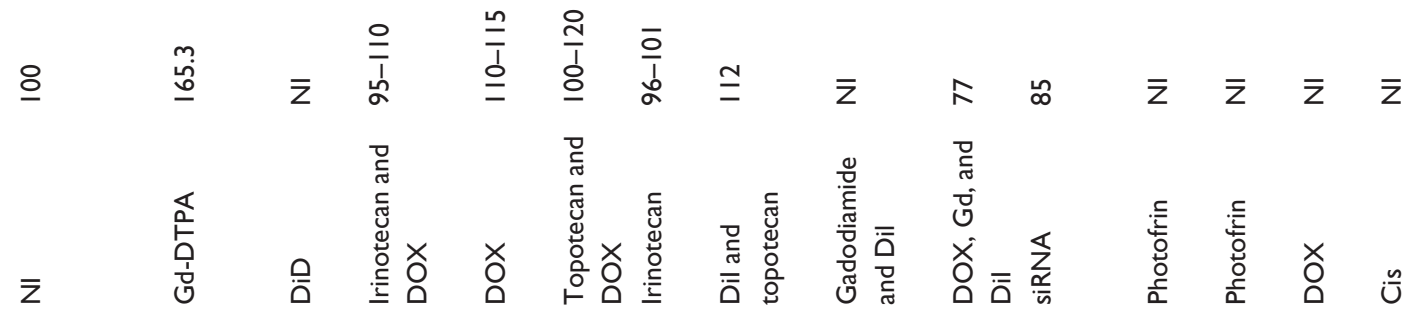

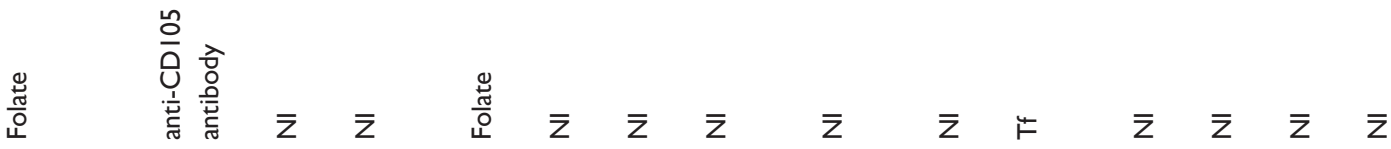

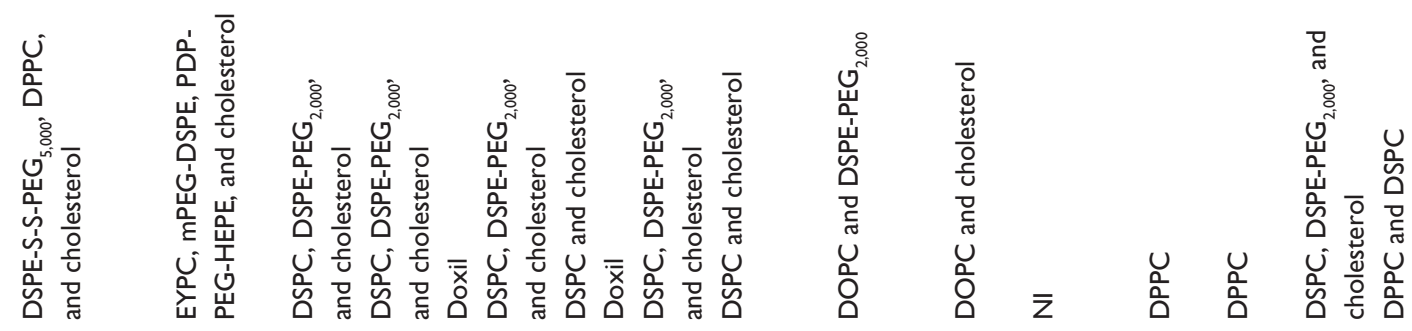

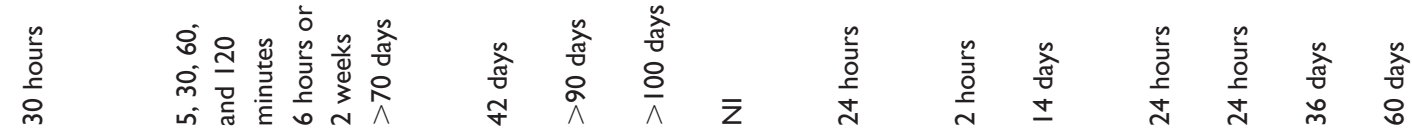

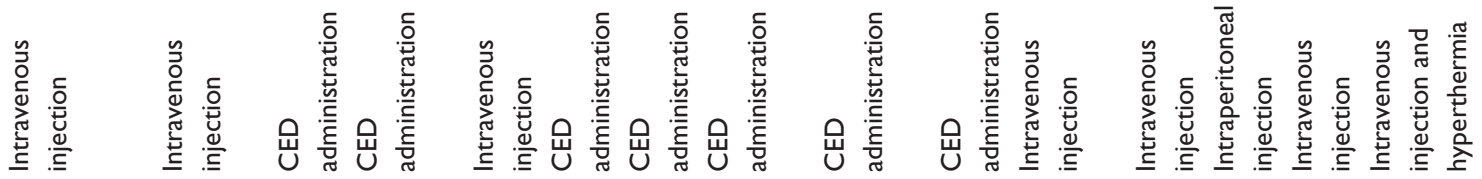

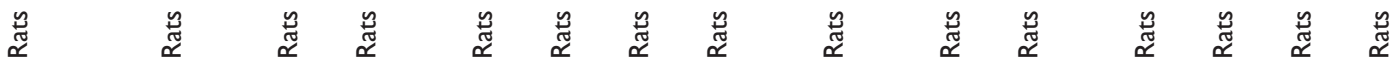




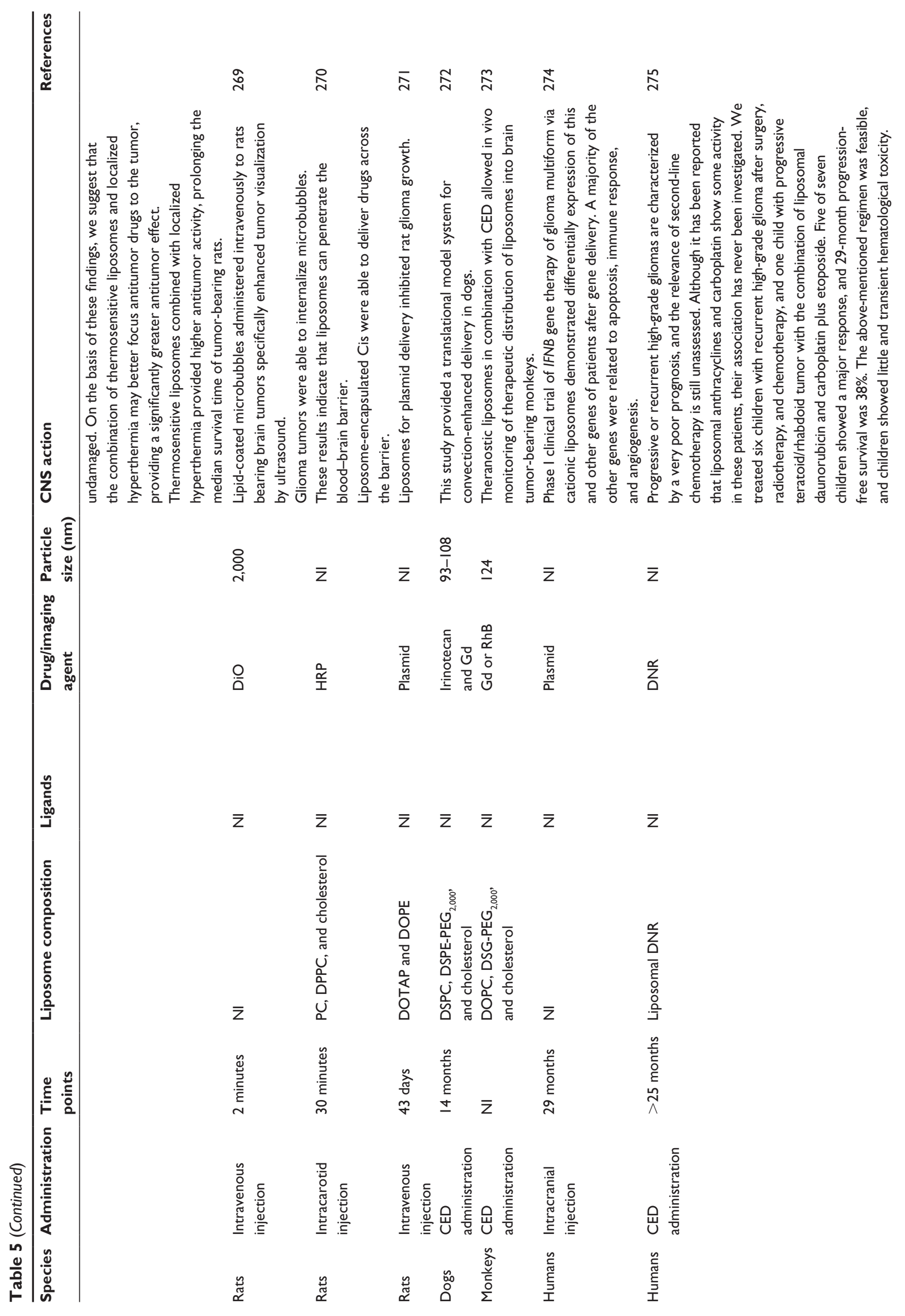




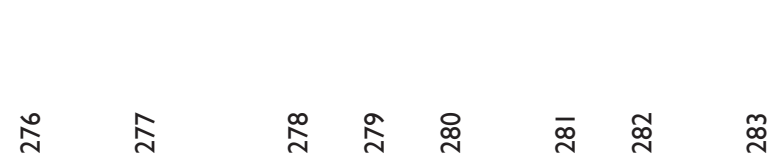

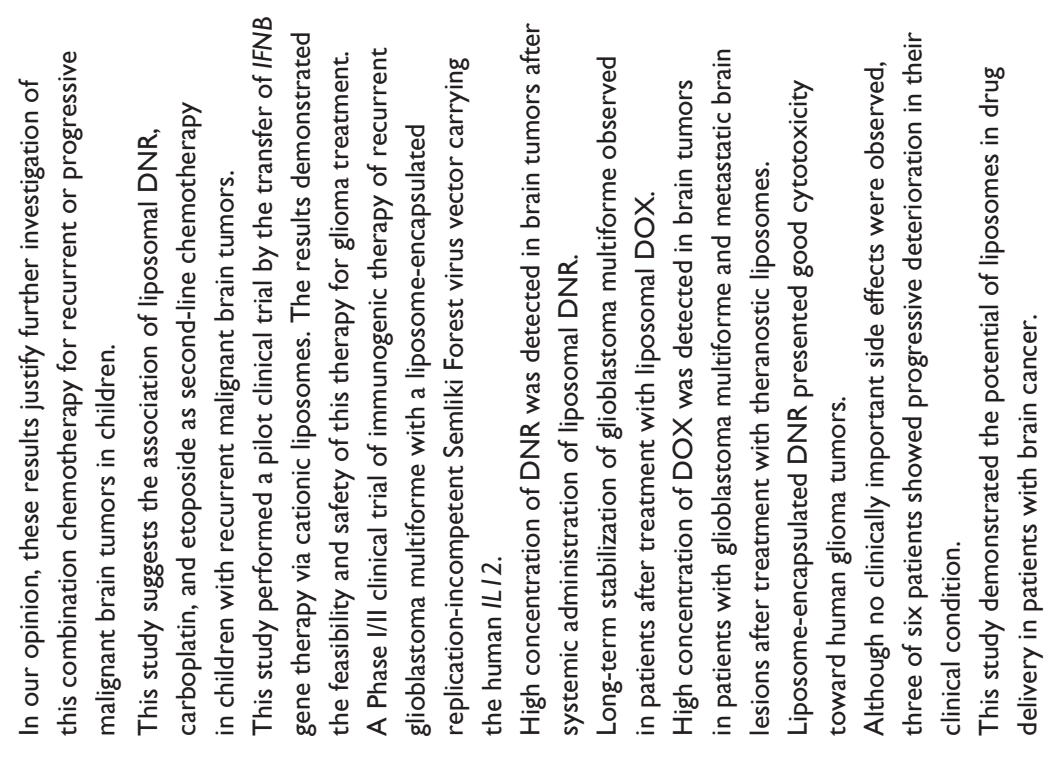

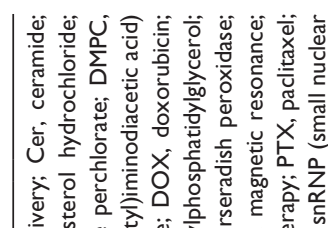

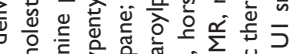

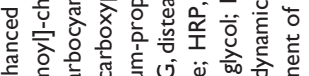

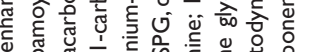

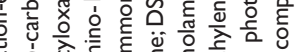

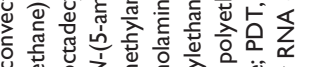

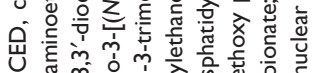

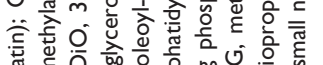

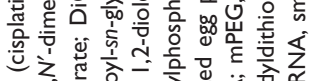

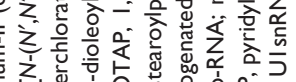

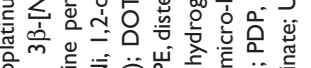

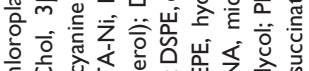

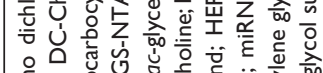

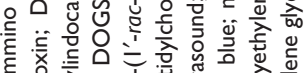

$$
\begin{aligned}
& \begin{array}{lllllllll}
\bar{z} & 8 & & \bar{z} & \bar{z} & \bar{z} & \bar{z} & \bar{z} & \bar{z}
\end{array}
\end{aligned}
$$

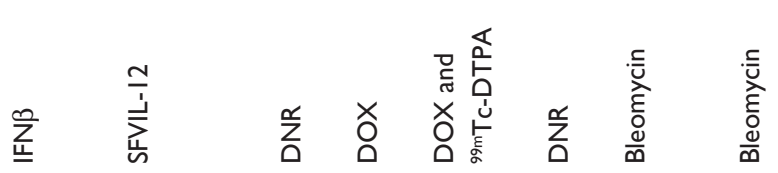

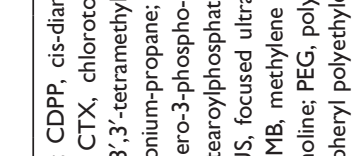

药

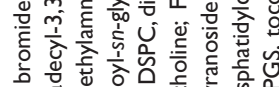

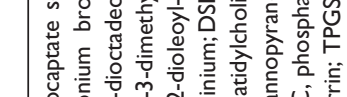

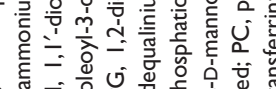

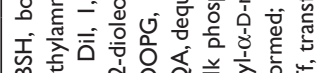

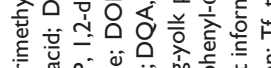

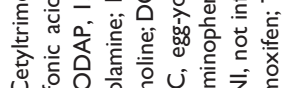

$\begin{array}{llllllllll}\bar{z} & \bar{z} & \bar{z} & \bar{z} & \bar{z} & \bar{z} & \bar{z} & \bar{z}\end{array}$

U U

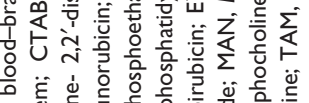

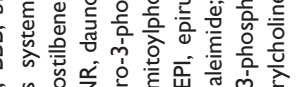

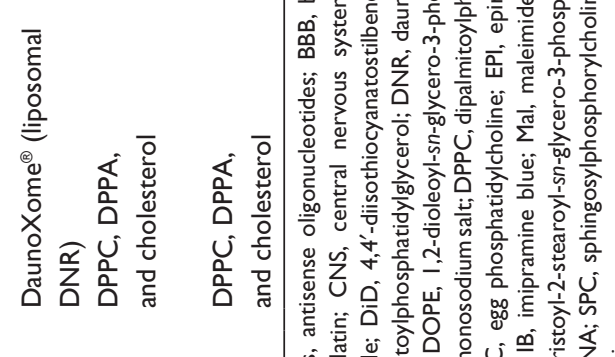

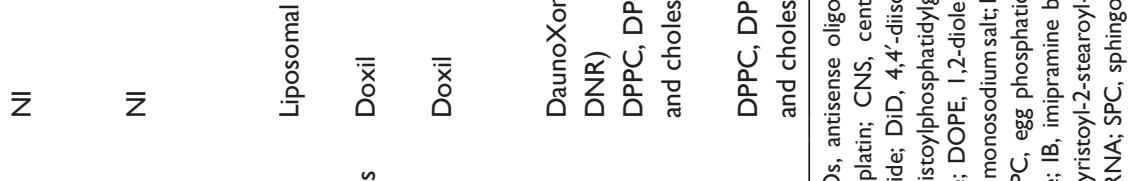

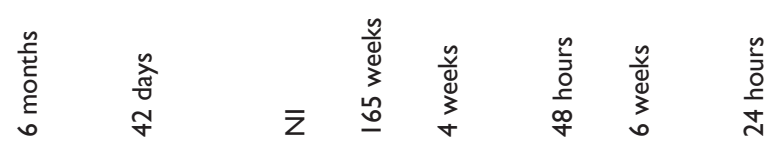

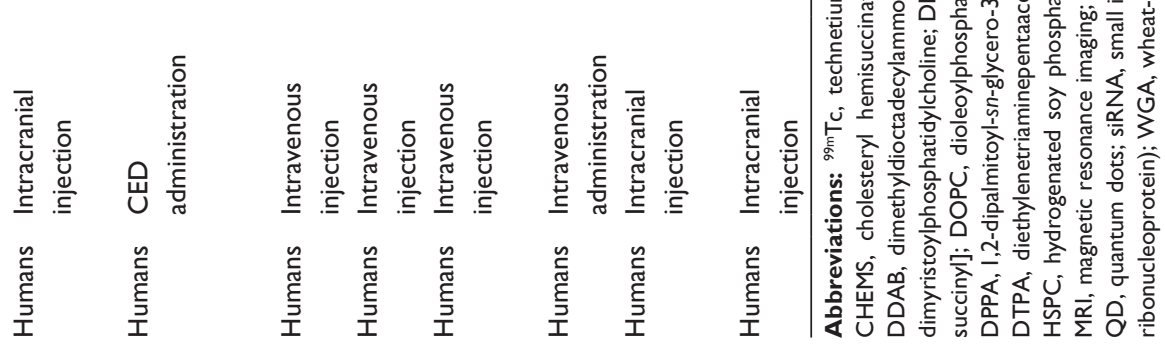


angiogenesis ${ }^{253}$ and delineate tumor margins, showing correlation between endoglin-associated neovasculature and tumor infiltration. ${ }^{231}$ In the same way, PET of Ala-Pro-ArgPro-Gly peptide-targeted liposomes was able specifically to image the different structure of glioma vessels. ${ }^{247}$ Also, liposome-targeted delivery of contrast agents containing antibodies to GFAP and the extracellular loop of $\mathrm{Cx} 43$ on its surface that selectively bound to brain-reactive astrocytes and faster-migrating glioma cells has been developed. ${ }^{239}$ Also developed have been PEGylated liposomes containing VEGF antibody on the surface, increasing the distribution and efficacy of the delivery of liposomes to glioma. ${ }^{233}$ However, it is still unclear if any of the strategies described could enhance detection of the earliest stage of tumors.

\section{Design of liposomal drug-delivery systems for glioma therapy}

Glioma therapy consists of surgery followed by radiotherapy, chemotherapy, or photodynamic therapy (PDT). Moreover, the stage and type of glioma often determines whether monotherapy or combined therapies are needed. Radiation therapy is a very common option for the treatment of gliomas, and has a variety of modalities, including external beam and brachytherapy. ${ }^{292}$ External beam radiotherapy, the most common approach in the clinic, uses ionizing radiation to kill cancer cells, but its application is limited by doses lower than 80 Gy due to toxicity. ${ }^{293}$ Brachytherapy or internal therapy uses a radioactive source that is delivered into or near the tumor itself, making it possible to deliver high radiation to the tumor and harming as few normal cells as possible. ${ }^{294} \mathrm{In}$ this way, recent studies suggest that brachytherapy with liposomally encapsulated ${ }^{186} \mathrm{Re}$ or ${ }^{188} \mathrm{Re}$ isotopes holds significant promise for glioma therapy. ${ }^{229,242,245}$ These studies demonstrated that animals treated with ${ }^{186} \mathrm{Re}$ or ${ }^{188} \mathrm{Re}$ liposomes had significantly prolonged survival, independent of the route of administration. ${ }^{229,242}$ Also, ${ }^{188} \mathrm{Re}$ liposomes have been explored for diagnostic evaluation, revealing the potential of these liposomes as a future theranostic agent for brain gliomas. ${ }^{245}$

A wide variety of liposome-encapsulated anticancer drugs have also been developed for both experimental and clinical oncology. By virtue of their unique physicochemical characteristics, liposomes have mainly shown improvement in the therapeutic index of chemotherapeutic drugs by enhancing their efficacy against aggressive and chemoresistant glioma cells and/or lowering drug side effects in the body. Antitumor antibiotics include doxorubicin (DOX), daunorubicin (DNR), and bleomycin. DOX, an anthracycline antibiotic, damages DNA by intercalation, inhibiting DNA synthesis or poisoning of topoisomerase II, by alteration of membrane function, or by generation of free radicals. ${ }^{295,296} \mathrm{DNR}$, also an anthracycline antibiotic similar in its chemical structure to DOX, acts through intercalation into DNA, metal ion chelation, and/or by free radical formation. ${ }^{296}$ Bleomycin, a polypeptide antibiotic, exerts its action by breaking the DNA double helix. ${ }^{297}$

Furthermore, antitumor antibiotics are among the most widely used and studied chemotherapeutic drugs. They are currently available in the market as free drugs (Adriamycin ${ }^{\circledR}$, Cerubidine $^{\circledR}$, and Blenoxane ${ }^{\circledR}$, trade names for DOX, DNR, and bleomycin, respectively), encapsulated in PEGylated liposomes (Doxil ${ }^{\circledR}$ [PEGylated form of liposomal DOX]), and encapsulated in conventional liposomes (Myocet ${ }^{\circledR}$ and DaunoXome ${ }^{\circledR}$ [liposomal DOX and DNR, respectively]). Although the anticancer activity of free drugs has been reported to be effective against gliomas cells in vitro, they present very poor efficacy in vivo, because these antibiotics do not readily cross the BBB ${ }^{298}$ In a rat brain-glioma model, prolonged survival of the animals was observed when PEGylated liposomes were used to deliver DOX. ${ }^{267}$ In contrast, in a cohort of patients with brain cancer, liposomal DOX, DNR, or bleomycin was found moderately effective against glioma. $275,278,279,281-283$

Based on the moderate efficacy of liposomal formulations against brain tumors, it is clear that more effective drug-delivery strategies are needed. One promising alternative strategy involves the combination of ultrasound and microbubbles to induce BBB opening for local and transient delivery of drugs into the brain, leading to improvement in chemotherapy treatment. ${ }^{226,228,243,265}$ Moreover, as Doxil has been already clinically approved for the treatment of some types of cancer, these results suggest that the use of ultrasonic microbubbles for glioma chemotherapy is highly clinically relevant. ${ }^{228,243}$ Other alternative strategies were found in this search. Researchers developed stimuli-responsive liposomes that were able to release DOX in a controlled manner in response to an external low-power radio frequency field ${ }^{209}$ or local temperature rise. ${ }^{218}$ Both strategies showed an improvement of DOX delivery across the BBB and prolonged survival time of animals.

In fact, over the years many liposomal formulations have been developed for the treatment of gliomas. Some formulations demonstrated their ability to improve activity of anticancer drugs in vivo, such as topotecan, ${ }^{220}$ irinotecan, ${ }^{214,230,235,259}$ arsenic trioxide, ${ }^{255}$ cisplatin, ${ }^{237,240,268}$ and oxaliplatin, ${ }^{237}$ and codelivery of synergistic two-drug combinations ${ }^{257,258}$ into brain tumor-bearing animal models. Other formulations 
demonstrated increased bioavailability of the bioactive compound celastrol, ${ }^{217}$ carriage of small molecules ${ }^{241}$ and large payloads, ${ }^{225,270}$ and enabled efficient gene therapy. ${ }^{271,274,276,277}$ Additionally, the design of liposomes that simultaneously carry imaging and therapeutic agents is promising for glioma therapy, since it allows the opportunity for real-time visualization of drug localization, drug delivery, and monitoring the tumor-therapy response. ${ }^{252,260,262,272,280}$ However, although passively targeting liposomes are the only ones used in clinical therapy, they suffer several limitations, such as low EPR effect within the brain, nonspecific uptake, and the crossing of both barriers. Therefore, methods for enhancing the targeting of liposomes to brain tumors were developed.

According to our search, liposomes actively targeting strategies for CNS delivery of anticancer drugs across the BBB are basically divided into adsorptive-mediated transcytosis (AMT) and receptor-mediated transcytosis (RMT). AMT is trigged by electrostatic interactions between the negatively charged surface of brain endothelial cells and the positively charged moieties of macromolecules. AMT-based drug delivery for glioma therapy was performed using the cationic cell-penetrating TAT peptide to functionalize the surface of liposomally encapsulated DOX. ${ }^{248}$ The authors demonstrated that the TAT peptide could penetrate the BBB, since DOX was efficiently delivered to brain tumor-bearing rats. ${ }^{248}$ However, this cationization strategy suffers from several limitations, such as instability of the system in the serum, nonspecific interactions, immunogenicity, and toxicity. ${ }^{202,299}$

RMT-based drug delivery has been widely explored for liposome targeting to the brain. This strategy relies on liposomal ligand interaction with the very specific receptor-mediated transport system in the BBB. In fact, there are several kinds of receptors that are expressed on the surface of endothelial cells of the barrier, such as transferrin and lactoferrin, that have been explored to facilitate the crossing of liposomes into the brain. Transferrin liposomes have been reported to be able to deliver borocaptate (BSH) and small interfering RNA (siRNA) into the CNS, which is highly significant, because these compounds do not readily cross the BBB..$^{224,246,263}$ In the same way, the covalent binding of lactoferrin to the liposome surface proved to be an effective strategy for the treatment of brain tumors. ${ }^{244}$

In glioma therapy, similarly to the BBB, the BBTB also represents a challenge for glioma-targeted delivery. ${ }^{300}$ Fortunately, many kinds of receptors are highly expressed in the BBTB (tumor vessels and/or glioma cells), and these receptors have been explored for the design of actively targeting liposomes for brain delivery of anticancer drugs across the BBTB.
For example, such ligands as chlorotoxin, ${ }^{206,215,221}$ TR peptide, ${ }^{205}$ RGERPPR peptides, ${ }^{216}$ folate, ${ }^{64,65}$ anti-EGFR antibody, ${ }^{222}$ and IL-13, ${ }^{223}$ have been successfully attached to the surface of liposomes. As a result, these decorated liposomes were able selectively to bind, target, and enhance uptake by glioma cells. In the same way, hemagglutinating virus of Japan liposomes have successfully delivered foreign genes into murine glioma cells, representing a good system for gene delivery. ${ }^{227}$

More recently, researchers have developed liposomes that can penetrate the BBB and targeting brain-cancer cells. This new system, known as dual-targeting liposomes, was produced to deliver DOX, ${ }^{211,213,238}$ DNR, ${ }^{250}$ epirubicin, ${ }^{249}$ topotecan, ${ }^{251}$ plasmids, ${ }^{236}$ and siRNA, ${ }^{212}$ and for codelivery of synergistic two-drug combinations. ${ }^{203,210}$ All of these dual-targeting liposomes proved to be effective in crossing the BBB and targeting glioma cells. It was also demonstrated that just angiopep-2 peptide was able to target BBB and glioma cells at the same time, ${ }^{219}$ and RGD peptide targeted both BBTB and tumor cells. ${ }^{204,207,209}$

PDT uses photosensitizing agents, such as Photofrin, for brain tumors, along with light of appropriated wavelength to kill glioma cells. The PDT cell-killing mechanism is directly related to the production of reactive oxygen species, which leads to cell apoptosis, with minimal side effects. ${ }^{301}$ Unfortunately, the efficiency of this therapy for gliomas is limited by the BBB. Just like for chemotherapy, the efficacy of PDT for the treatment of brain tumors was greatly improved when Photofrin was encapsulated into liposomes, since the photosensitizing agent was efficiently delivered within brain tumors. ${ }^{264,266}$ Finally, it is worth mentioning here that although the preferred route for delivery of liposomes seems to be intravenous injection, alternative routes of administration, such as convection-enhanced delivery and intracranial, intracarotid, and intraperitoneal injections, have been also considered.

\section{Conclusion}

The BBB is the most important obstacle to effective brain drug delivery. There has been great interest in this area, especially in the development of targeted liposomes to cross the BBB and to deliver therapeutic molecules only to the disease site within the brain. From the reported articles, we could see that liposomes can get into the brain via different mechanisms. Examples of these mechanisms are: 1) transport of liposomes via RMT, followed by their internalization by neurons or glial cells and release of therapeutic molecules within those cells; 2) adsorption of cationic liposomes in the endothelial cells, which enhanced the concentration of 
therapeutic molecules within the brain cells; 3) antibody- or peptide-conjugated liposomes used to transport and target encapsulated drugs into the brain via transcytotic pathways; 4) inhibition of efflux transporters, such as PgP, by coating liposomes with transporter-inhibitory substances; and 5) disruption of the BBB. In fact, liposomes have the potential to revolutionize drug development for therapy and/or diagnosis of neurological diseases. By their unique physicochemical properties, liposomes have shown great ability to compartmentalize and solubilize hydrophilic and hydrophobic drugs (Figure 4). Furthermore, liposomes are biocompatible and biodegradable systems, which make them suitable for neuromedicine.

Also, the functionalization of liposomes surface modified with antibodies, peptides, aptamers, and other small molecules has shown promise in delivering a huge range of therapeutic molecules to targeted sites in the body (Figure 4). Liposomes usually improve the therapeutic index of new or established drugs by prolonging biological half-life and reducing their side effects. More importantly, liposomes may provide an excellent therapeutic tool for treatment or diagnosis of neurological disorders, due to their ability to cross the BBB and efficiently deliver drugs and/or contrast agents into the CNS, as discussed in this article. Additionally, theranostic liposomes have been developed, allowing real-time therapeutic efficacy. Also, high efficacy in using liposomes to deliver a drug in a spatial and temporal manner has been demonstrated (Figure 4), which we believe may be critical for the success of more effective therapy for neurological diseases.

Unfortunately, most advances and breakthroughs in liposome-based approaches have just happened for glioma therapy. The development of effective therapy for AD, PD, and stroke has been largely constrained. This might be due to our deficiency in understanding the neurological mechanisms and pathogenesis of these disorders. Increasing our comprehension about these diseases will contribute to the development of novel potential therapeutic strategies. This is essential, since we are living in a modern aging society and an effective spectrum of treatments is urgently needed.

By crossing the BBB, achieving efficient drug delivery into the brain is possible, which leads to an intensive search for alternative administration routes for liposomes. In this review, various studies used different administration routes to access the brain for the therapeutic delivery of liposomes (Figure 4). Intravenous injection of liposomes was the preferred route in the majority of the works cited here. Alternatively, intranasal injections offered a direct mode of drug delivery into the brain for AD and PD. Convection-enhanced delivery provided interesting results

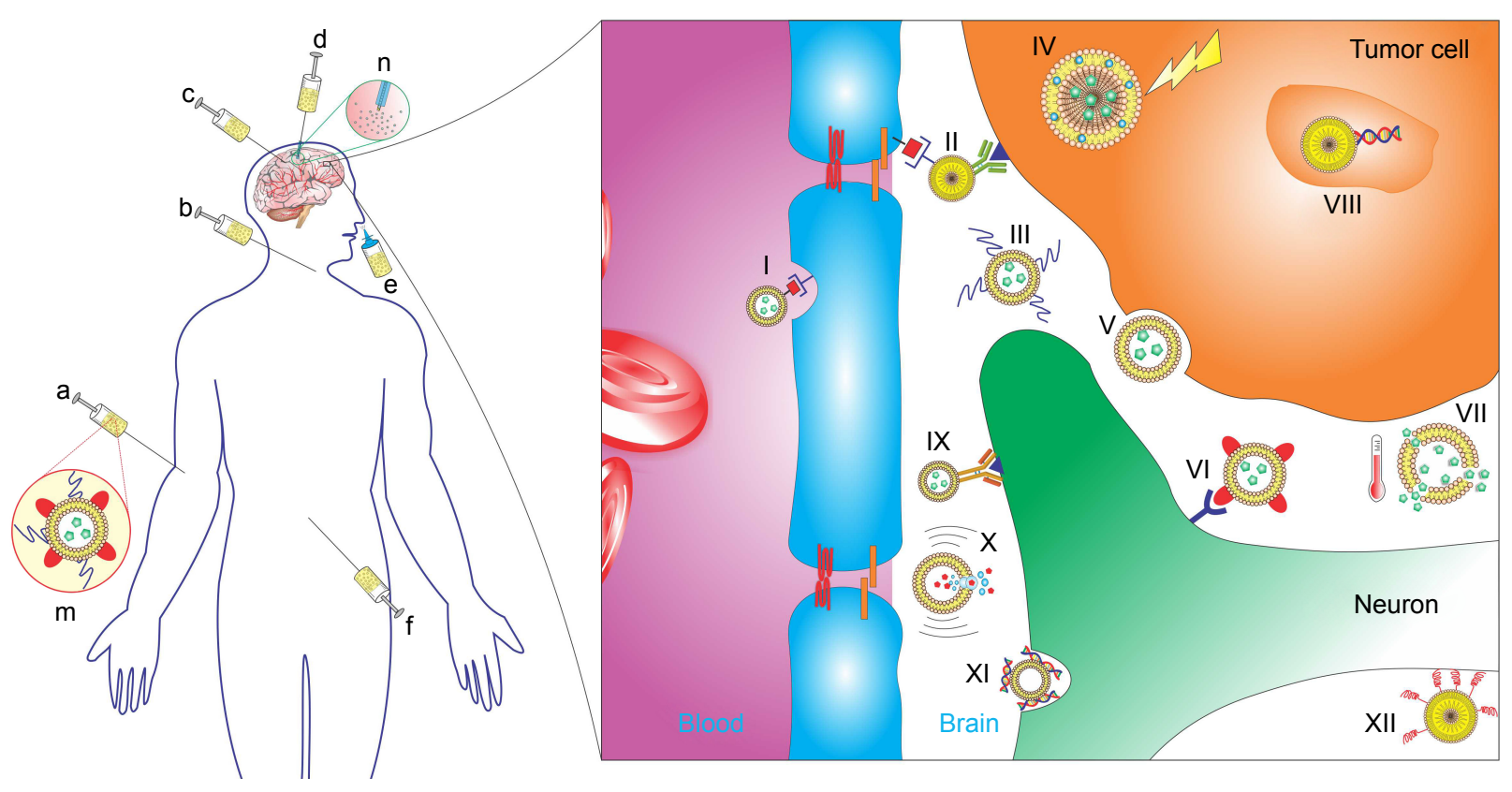

Figure 4 Delivery of therapeutic molecules or imaging agents to the brain by liposomes $(\mathrm{m})$ is highly challenging.

Notes: Liposomes can be administered to the central nervous system via systemic delivery (a), intracarotid (b), intracranial (c), intranasal (e), and intraperitoneal ( $f$ ) injections, or via convection-enhanced delivery $(\mathrm{d} / \mathrm{n})$. Liposome-based strategies consist in encapsulating the molecules of interest in liposomes $(\mathrm{V})$. The ability to increase their bloodcirculation time is created with the ligation of polyethylene glycol on the liposome surface (III). Liposomes can also be targeted to cross the blood-brain barrier (I), target the site of disease (IX), or both (II). Surface modification of liposomes can be achieved by covalent ligation of antibodies (IX), RNA aptamers (VI), or peptides (XII). Cationic lipids can be incorporated into the bilayer, facilitating their association with nucleic acids for gene therapy (VIII and XI). This figure also summarizes therapeutic mechanisms, such as hyperthermia (IV), temperature increase (VII), and ultrasound (X). 
for efficient delivery of liposomes for drug delivery to tumor-bearing animal models (Tables 3-5). Administration of liposomal formulation via nonparenteral routes is highly desirable, since effective strategies for crossing the BBB are urgently needed.

\section{Disclosure}

The authors report no conflicts of interest in this work.

\section{References}

1. Ehrlich P. Das Sauerstoff-Bedürfnis des Organismus: Eine Farbenanalytische Studie [The oxygen demand of the organism: a color analysis study]. Berlin: Hirschwald; 1885.

2. Goldmann EE. Vitalfarbung am Zentralnervensystem: Beitrag zur Physio-Pathologie des Plexus Chorioideus und der Hirnhäute [Vital staining of the central nervous system: contribution to the physiopathology of the plexus choroid and the brain membranes]. Berlin: Königlich Akademie der Wissenschaften; 1913. German.

3. Lewandowsky M. Zur lehre der cerebrospinal flüssigkeit [For the teaching of cerebrospinal fluid]. Z Klin Med. 1900;40:480-494. German.

4. Reese TS, Karnovsky MJ. Fine structural localization of a blood-brain barrier to exogenous peroxidase. J Cell Biol. 1967;34:207-217.

5. Hawkins BT, Davis TP. The blood-brain barrier/neurovascular unit in health and disease. Pharmacol Rev. 2005;57:173-185.

6. Pardridge WM. Blood-brain barrier delivery. Drug Discov Today. 2007; 12:54-61.

7. Abbott NJ, Rönnbäck L, Hansson E. Astrocyte-endothelial interactions at the blood-brain barrier. Nat Rev Neurosci. 2006;7:41-53.

8. Ballabh P, Braun A, Nedergaard M. The blood-brain barrier - an overview: structure, regulation, and clinical implications. Neurobiol Dis. 2004;16:1-13.

9. Abbott NJ, Patabendige AA, Dolman DE, Yusof SR, Begley DJ. Structure and function of the blood-brain barrier. Neurobiol Dis. 2010; 37:13-25.

10. Vorbrodt AW. Ultracytochemical characterization of anionic sites in the wall of brain capillaries. J Neurocytol. 1989;18:359-368.

11. Scherrmann JM. Drug delivery to brain via the blood-brain barrier. Vascul Pharmacol. 2002;38:349-354.

12. Poduri A, Evrony GD, Cai X, Walsh CA. Somatic mutation, genomic variation, and neurological disease. Science. 2013;341:1237758.

13. Qureshi IA, Mehler MF. Epigenetic mechanisms underlying the pathogenesis of neurogenetic diseases. Neurotherapeutics. 2014;11: 708-720.

14. Lesniak MS, Brem H. Targeted therapy for brain tumours. Nat Rev Drug Discov. 2004;3:499-508.

15. Stenehjem DD, Hartz AM, Bauer B, Anderson GW. Novel and emerging strategies in drug delivery for overcoming the blood-brain barrier. Future Med Chem. 2009;1:1623-1641.

16. Pavan B, Dalpiaz A, Ciliberti N, Biondi C, Manfredini S, Vertuani S. Progress in drug delivery to the central nervous system by the prodrug approach. Molecules. 2008;13:1035-1065.

17. Gabathuler R. Approaches to transport therapeutic drugs across the blood-brain barrier to treat brain diseases. Neurobiol Dis. 2010;37: 48-57.

18. Pardridge WM. Drug delivery to the brain. J Cereb Blood Flow Metab. 1997; 17:713-731.

19. Banks WA. From blood-brain barrier to blood-brain interface: new opportunities for CNS drug delivery. Nat Rev Drug Discov. 2016;15: 275-292.

20. Fleming AB, Saltzman WM. Pharmacokinetics of the carmustine implant. Clin Pharmacokinet. 2002;41:403-419.

21. Barua NU, Gill SS, Love S. Convection-Enhanced drug delivery to the brain: therapeutic potential and neuropathological considerations. Brain Pathol. 2014;24:117-127.
22. Aryal M, Arvanitis CD, Alexander PM, McDannold N. Ultrasoundmediated blood-brain barrier disruption for targeted drug delivery in the central nervous system. Adv Drug Deliv Rev. 2014;72:94-109.

23. King A. Breaking through the barrier. Chem World. 2011;8:36-39.

24. Bertrand Y, Currie JC, Poirier J, et al. Influence of glioma tumour microenvironment on the transport of ANG1005 via low-density lipoprotein receptor-related protein 1. Br J Cancer. 2011;105: 1697-1707.

25. Spencer BJ, Verma IM. Targeted delivery of proteins across the bloodbrain barrier. Proc Natl Acad Sci U S A. 2007;104:7594-7599.

26. Ché C, Yang G, Thiot C, et al. New Angiopep-modified doxorubicin (ANG1007) and etoposide (ANG1009) chemotherapeutics with increased brain penetration. J Med Chem. 2010;53:2814-2824.

27. Vlieghe P, Khrestchatisky M. Medicinal chemistry based approaches and nanotechnology-based systems to improve CNS drug targeting and delivery. Med Res Rev. 2013;33:457-516.

28. Bhaskar S, Tian F, Stoeger T, et al. Multifunctional nanocarriers for diagnostics, drug delivery and targeted treatment across blood-brain barrier: perspectives on tracking and neuroimaging. Part Fibre Toxicol. 2010;7:3.

29. Lai F, Fadda AM, Sinico C. Liposomes for brain delivery. Expert Opin Drug Deliv. 2013;10:1003-1022.

30. Ramos-Cabrer P, Campos F. Liposomes and nanotechnology in drug development: focus on neurological targets. Int J Nanomedicine. 2013; 8:951-960.

31. Kreuter J. Drug delivery to the central nervous system by polymeric nanoparticles: What do we know? Adv Drug Deliv Rev. 2014;71:2-14.

32. Patel T, Zhou J, Piepmeier JM, Saltzman WM. Polymeric nanoparticles for drug delivery to the central nervous system. Adv Drug Deliv Rev. 2012;64:701-705.

33. Ren J, Shen S, Wang D, et al. The targeted delivery of anticancer drugs to brain glioma by PEGylated oxidized multi-walled carbon nanotubes modified with angiopep-2. Biomaterials. 2012;33:3324-3333.

34. Al-Jamal KT, Gherardini L, Bardi G, et al. Functional motor recovery from brain ischemic insult by carbon nanotube-mediated siRNA silencing. Proc Natl Acad Sci U S A. 2011;108:10952-10957.

35. Tseng Y, Kao Y, Liao J, Chen W, Liu S. Biodegradable drug-eluting poly(lactic-co-glycol acid) nanofibers for the sustainable delivery of vancomycin to brain tissue: in vitro and in vivo studies. ACS Chem Neurosci. 2013;4:1314-1321.

36. Xie J, Wang CH. Electrospun micro- and nanofibers for sustained delivery of paclitaxel to treat C6 Glioma in vitro. Pharm Res. 2006;23: 1817-1826.

37. Somani S, Dufès C. Applications of dendrimers for brain delivery and cancer therapy. Nanomedicine (Lond). 2014;9:2403-2414.

38. Pérez-Martínez FC, Ocaña AV, Pérez-Carrión MD, Ceña V. Dendrimers as vectors for genetic material delivery to the nervous system. Curr Med Chem. 2012;19:5101-5108.

39. Morshed RA, Cheng Y, Auffinger B, Wegscheid ML, Lesniak MS. The potential of polymeric micelles in the context of glioblastoma therapy. Front Pharmacol. 2013;4:157.

40. Sharma HS, Menon PK, Lafuente JV, et al. The role of functionalized magnetic iron oxide nanoparticles in the central nervous system injury and repair: new potentials for neuroprotection with Cerebrolysin therapy. J Nanosci Nanotechnol. 2014;14:577-595.

41. Li W, Chen X. Gold nanoparticles for photoacoustic imaging. Nanomedicine (Lond). 2015;10:299-320.

42. World Health Organization. Neurological Disorders: Public Health Challenges. Geneva: WHO; 2006.

43. Micheli MR, Bova R, Magini A, Polidoro M, Emiliani C. Lipid-based nanocarriers for CNS-targeted drug delivery. Recent Pat CNS Drug Discov. 2012;7:71-86.

44. Schnyder A, Huwyler J. Drug transport to brain with targeted liposomes. NeuroRX. 2005;2:99-107.

45. Johnsen KB, Moos T. Revisiting nanoparticle technology for bloodbrain barrier transport: unfolding at the endothelial gate improves the fate of transferrin receptor-targeted liposomes. $J$ Control Release. 2016;222:32-46. 
46. Noble GT, Stefanick JF, Ashley JD, Kiziltepe T, Bilgicer B. Ligandtargeted liposome design: challenges and fundamental considerations. Trends Biotechnol. 2014:32:32-45.

47. Torchilin VP. Recent advances with liposomes as pharmaceutical carriers. Nat Rev Drug Discov. 2005;4:145-160.

48. Loyse A, Thangaraj H, Easterbrook P, et al. Cryptococcal meningitis: improving access to essential antifungal medicines in resource-poor countries. Lancet Infect Dis. 2013;13:629-637.

49. Robinson RF, Nahata MC. A comparative review of conventional and lipid formulations of amphotericin B. J Clin Pharm Ther. 1999;24: 249-257.

50. Lippens RJ. Liposomal daunorubicin (DaunoXome) in children with recurrent or progressive brain tumors. Pediatr Hematol. 1999;16: 131-139.

51. Benesch M, Urban C. Liposomal cytarabine for leukemic and lymphomatous meningitis: recent developments. Expert Opin Pharmacother. 2008;9:301-309.

52. Ananda S, Nowak AK, Cher L, et al. Phase 2 trial of temozolomide and PEGylated liposomal doxorubicin in the treatment of patients with glioblastoma multiforme following concurrent radiotherapy and chemotherapy. J Clin Neurosci. 2011;18:1444-1448.

53. Beier CP, Schmid C, Gorlia T, et al. RNOP-09: PEGylated liposomal doxorubicine and prolonged temozolomide in addition to radiotherapy in newly diagnosed glioblastoma - a phase II study. BMC Cancer. 2009;9:308.

54. Hau P, Fabel K, Baumgart U, et al. PEGylated liposomal doxorubicinefficacy in patients with recurrent high-grade glioma. Cancer. 2004;100: 1199-1207.

55. Chua SL, Rosenthal MA, Wong SS, et al. Phase 2 study of temozolomide and Caelyx in patients with recurrent glioblastoma multiforme. Neuro Oncol. 2004;6:38-43.

56. Wagner S, Peters O, Fels C, et al. PEGylated-liposomal doxorubicin and oral topotecan in eight children with relapsed high-grade malignant brain tumors. J Neurooncol. 2008;86:175-181.

57. Marina NM, Cochrane D, Harney E, et al. Dose escalation and pharmacokinetics of PEGylated liposomal doxorubicin (Doxil) in children with solid tumors: a pediatric oncology group study. Clin Cancer Res. 2002;8:413-418.

58. Di Legge A, Trivellizzi IN, Moruzzi MC, Pesce A, Scambia G, Lorusso D. Phase 2 trial of nonPEGylated doxorubicin (Myocet) as second-line treatment in advanced or recurrent endometrial cancer. Int $J$ Gynecol Cancer. 2011;21:1446-1451.

59. Vieira DB, Gamarra LF. Advances in the use of nanocarriers for cancer diagnosis and treatment. Einstein (Sao Paulo). 2016;14:99-103.

60. Joshi S, Singh-Moon RP, Ellis JA, et al. Cerebral hypoperfusion-assisted intra-arterial deposition of liposomes in normal and glioma-bearing rats. Neurosurgery. 2015;76:92-100.

61. Joshi S, Singh-Moon R, Wang M, et al. Cationic surface charge enhances early regional deposition of liposomes after intracarotid injection. J Neurooncol. 2014;120:489-497.

62. Joshi S, Singh-Moon RP, Wang M, et al. Transient cerebral hypoperfusion assisted intraarterial cationic liposome delivery to brain tissue. J Neurooncol. 2014;118:73-82.

63. Huwyler J, Wu D, Pardridge WM. Brain drug delivery of small molecules using immunoliposomes. Proc Natl Acad Sci U S A. 1996;93: 14164-14169.

64. McNeeley KM, Annapragada A, Bellamkonda RV. Decreased circulation time offsets increased efficacy of PEGylated nanocarriers targeting folate receptors of glioma. Nanotechnology. 2007;18: 385101.

65. McNeeley KM, Karathanasis E, Annapragada AV, Bellamkonda RV. Masking and triggered unmasking of targeting ligands on nanocarriers to improve drug delivery to brain tumors. Biomaterials. 2009;30: 3986-3995.

66. Ding H, Sagar V, Agudelo M, et al. Enhanced blood-brain barrier transmigration using a novel transferrin embedded fluorescent magnetoliposome nanoformulation. Nanotechnology. 2014;25:055101.
67. Nair MPN, Saiyed SM, inventors; The Florida International University Board Of Trustees, assignee. Magnetic nanodelivery of therapeutic agents across the blood brain barrier. United States patent US 20110213193 A1. 2011 Sep 1.

68. Guo H, Chen W, Sun X, Liu YN, Li J, Wang J. Theranostic magnetoliposomes coated by carboxymethyl dextran with controlled release by low-frequency alternating magnetic field. Carbohydr Polym. 2015; 118:209-217.

69. Shazeeb MS, Feula G, Bogdanov A. Liposome-encapsulated superoxide dismutase mimetic: theranostic potential of an MR detectable and neuroprotective agent. Contrast Media Mol Imaging. 2014;9: 221-228.

70. Karmali PP, Chaudhuri A. Cationic liposomes as non-viral carriers of gene medicines: resolved issues, open questions, and future promises. Med Res Rev. 2007;27:696-722.

71. Dass CR, Choong PF. Targeting of small molecule anticancer drugs to the tumour and its vasculature using cationic liposomes: lessons from gene therapy. Cancer Cell Int. 2006;6:17.

72. Chen W, Li H, Liu Z, Yuan W. Lipopolyplex for therapeutic gene delivery and its application for the treatment of Parkinson's disease. Front Aging Neurosci. 2016;8:68

73. Lajoie JM, Shusta EV. Targeting receptor-mediated transport for delivery of biologics across the blood-brain barrier. Anпu Rev Pharmacol Toxicol. 2015;55:613-631.

74. McConnell EM, Holahan MR, DeRosa MC. Aptamers as promising molecular recognition elements for diagnostics and therapeutics in the central nervous system. Nucleic Acid Ther. 2014;24:388-404.

75. Kelkar SS, Reineke TM. Theranostics: combining imaging and therapy. Bioconjug Chem. 2011;22:1879-1903.

76. Wen CJ, Zhang LW, Al-Suwayeh SA, Yen TC, Fang JY. Theranostic liposomes loaded with quantum dots and apomorphine for brain targeting and bioimaging. Int J Nanomedicine. 2012;7:1599-1611.

77. Lerner EN, van Zanten EH, Stewart GR. Enhanced delivery of octreotide to the brain via transnasal iontophoretic administration. J Drug Target. 2004;12:273-280.

78. Mistry A, Stolnik S, Illum L. Nanoparticles for direct nose-to-brain delivery of drugs. Int J Pharm. 2009;379:146-157.

79. Wu H, Hu K, Jiang X. From nose to brain: understanding transport capacity and transport rate of drugs. Expert Opin Drug Deliv. 2008;5: $1159-1168$

80. Arumugam K, Subramanian GS, Mallayasamy SR, Averineni RK, Reddy MS, Udupa N. A study of rivastigmine liposomes for delivery into the brain through intranasal route. Acta Pharm. 2008;58: 287-297.

81. Migliore MM, Vyas TK, Campbell RB, Amiji MM, Waszczak BL. Brain delivery of proteins by the intranasal route of administration: a comparison of cationic liposomes versus aqueous solution formulations. J Pharm Sci. 2010;99:1745-1761.

82. Ross CA, Poirier MA. Protein aggregation and neurodegenerative disease. Nat Med. 2004;10:S10-S17.

83. Rotman M, Welling MM, Bunschoten A, et al. Enhanced glutathione PEGylated liposomal brain delivery of an anti-amyloid single domain antibody fragment in a mouse model for Alzheimer's disease. J Control Release. 2015;203:40-50.

84. Balducci C, Mancini S, Minniti S, et al. Multifunctional liposomes reduce brain $\beta$-amyloid burden and ameliorate memory impairment in Alzheimer's disease mouse models. J Neurosci. 2014;34:14022-14031.

85. Bana L, Minniti S, Salvati E, et al. Liposomes bi-functionalized with phosphatidic acid and an ApoE-derived peptide affect $\mathrm{A} \beta$ aggregation features and cross the blood-brain-barrier: implications for therapy of Alzheimer disease. Nanomedicine. 2014;10:1583-1590.

86. Mutlu NB, Değim Z, Yılmaz S, Eşsiz D, Nacar A. New perspective for the treatment of Alzheimer diseases: liposomal rivastigmine formulations. Drug Dev Ind Pharm. 2011;37:775-789.

87. Tanifum EA, Dasgupta I, Srivastava M, et al. Intravenous delivery of targeted liposomes to amyloid- $\beta$ pathology in APP/PSEN1 transgenic mice. PLoS One. 2012;7:e48515. 
88. Chen ZL, Huang M, Wang XR, et al. Transferrin-modified liposome promotes $\alpha$-mangostin to penetrate the blood-brain barrier. Nanomedicine. 2016;12:421-430.

89. Ordóñez-Gutiérrez L, Re F, Bereczki E, et al. Repeated intraperitoneal injections of liposomes containing phosphatidic acid and cardiolipin reduce amyloid- $\beta$ levels in APP/PS1 transgenic mice. Nanomedicine. 2015;11:421-430.

90. Yang ZZ, Zhang YQ, Wang ZZ, Wu K, Lou JN, Qi XR. Enhanced brain distribution and pharmacodynamics of rivastigmine by liposomes following intranasal administration. Int J Pharm. 2013;452:344-354.

91. Ismail MF, Elmeshad AN, Salem NA. Potential therapeutic effect of nanobased formulation of rivastigmine on rat model of Alzheimer's disease. Int J Nanomedicine. 2013;8:393-406.

92. Li W, Zhou Y, Zhao N, Hao B, Wang X, Kong P. Pharmacokinetic behavior and efficiency of acetylcholinesterase inhibition in rat brain after intranasal administration of galanthamine hydrobromide loaded flexible liposomes. Environ Toxicol Pharmacol. 2012;34:272-279.

93. Tong-Un T, Muchimapura S, Phachonpai W, Wattanathorn J. Nasal administration of quercetin liposomes modulate cognitive impairment and inhibit acetylcholinesterase activity in hippocampus. Am J Neurosci. 2010;1:21-27.

94. Phachonpai W, Wattanathorn J, Muchimapura S, Preechagoon D. Neuroprotective effect of quercetin encapsulated liposomes: a novel therapeutic strategy against Alzheimer's disease. Am J Appl Sci. 2010 7:480-485.

95. Wattanatho J, Phachonpai W, Priprem A, Suthiparin S. Intranasal administration of quercetin liposome decreases anxiety-like behavior and increases spatial memory. Am J Agric Biol Sci. 2007;2:31-35.

96. Xiang Y, Wu Q, Liang L, et al. Chlorotoxin-modified stealth liposomes encapsulating levodopa for the targeting delivery against the Parkinson's disease in the MPTP-induced mice model. J Drug Target. 2012;20:67-75

97. Kucherianu VG, Iurasov VV, Kryzhanovskiı̌ GN, et al. [The effect of liposomal form of L-Dopa on the development of parkinsonian syndrome in mice]. Biull Eksp Biol Med. 1997;123:29-33. Russian.

98. Yurasov VV, Kucheryanu VG, Kudrin VS, et al. Effect of long-term parenteral administration of empty and L-Dopa-loaded liposomes on the turnover of dopamine and its metabolites in the striatum of mice with experimental Parkinson's syndrome. Bull Exp Biol Med. 1997 123:126-129.

99. Yurasov VV, Podgornyi GN, Kucheryanu VG, et al. Effects of L-Dopa-carrying liposomes on striatal concentration of dopamine and its metabolites and phospholipid metabolism in experimental Parkinson's syndrome. Bull Exp Biol Med. 1996;122:1180-1183.

100. Migliore MM, Ortiz R, Dye S, Campbell RB, Amiji MM, Waszczak BL. Neurotrophic and neuroprotective efficacy of intranasal GDNF in a rat model of Parkinson's disease. Neuroscience. 2014;274:11-23.

101. Xia CF, Boado RJ, Zhang Y, Chu C, Pardridge WM. Intravenous glialderived neurotrophic factor gene therapy of experimental Parkinson's disease with Trojan horse liposomes and a tyrosine hydroxylase promoter. J Gene Med. 2008;10:306-315.

102. Di Stefano A, Sozio P, Iannitelli A, Marianecci C, Santucci E, Carafa M. Maleic- and fumaric-diamides of (O,O-diacetyl)-L-Dopa-methylester as anti-Parkinson prodrugs in liposomal formulation. J Drug Target 2006; 14:652-661.

103. Di Stefano A, Carafa M, Sozio P, et al. Evaluation of rat striatal L-dopa and DA concentration after intraperitoneal administration of L-dopa prodrugs in liposomal formulations. $J$ Control Release. 2004;99:293-300.

104. Krstic D, Knuesel I. Deciphering the mechanism underlying late-onset Alzheimer disease. Nat Rev Neurol. 2012;9:25-34.

105. Lipton $\mathrm{SA}, \mathrm{Gu} Z$, Nakamura T. Inflammatory mediators leading to protein misfolding and uncompetitive/fast off-rate drug therapy for neurodegenerative disorders. Int Rev Neurobiol. 2007;82:1-27.

106. Moreira PI, Siedlak SL, Aliev G, et al. Oxidative stress mechanisms and potential therapeutics in Alzheimer disease. J Neural Transm (Vienna). 2005;112:921-932.
107. Oddo S, LaFerla FM. The role of nicotinic acetylcholine receptors in Alzheimer's disease. J Physiol Paris. 2006;99:172-179.

108. Wenk GL, Rosi S, McGann K, Hauss-Wegrzyniak B. A nitric oxidedonating flurbiprofen derivative reduces neuroinflammation without interacting with galantamine in the rat. Eur J Pharmacol. 2002;453: 319-324.

109. Kan MJ, Lee JE, Wilson JG, et al. Arginine deprivation and immune suppression in a mouse model of Alzheimer's disease. JNeurosci. 2015; 35:5969-5982.

110. Hansen RA, Gartlehner G, Webb AP, Morgan LC, Moore CG, Jonas DE. Efficacy and safety of donepezil, galantamine, and rivastigmine for the treatment of Alzheimer's disease: a systematic review and metaanalysis. Clin Interv Aging. 2008;3:211-225.

111. Confaloni A, Tosto G, Tata A. Promising therapies for Alzheimer's disease. Curr Pharm Des. 2016;22:2050-2056.

112. Zheng X, Shao X, Zhang C, et al. Intranasal H102 peptide-loaded liposomes for brain delivery to treat Alzheimer's disease. Pharm Res. 2015;32:3837-3849.

113. Lazar AN, Mourtas S, Youssef I, et al. Curcumin-conjugated nanoliposomes with high affinity for $\mathrm{A} \beta$ deposits: possible applications to Alzheimer disease. Nanomedicine. 2013;9:712-721.

114. Theunis C, Crespo-Biel N, Gafner V, et al. Efficacy and safety of a liposome-based vaccine against protein tau, assessed in tau.P301L mice that model tauopathy. PLoS One. 2013;8:e72301.

115. Carrera I, Etcheverría I, Li Y, et al. Immunocytochemical characterization of Alzheimer disease hallmarks in APP/PS1 transgenic mice treated with a new anti-amyloid- $\beta$ vaccine. Biomed Res Int 2013;2013:709145.

116. Nicolau C, Greferath R, Balaban TS, Lazarte JE, Hopkins RJ A liposome-based therapeutic vaccine against $\beta$-amyloid plaques on the pancreas of transgenic NORBA mice. Proc Natl Acad Sci US A. 2002;99:2332-2337.

117. Lee HJ, Bae EJ, Lee SJ. Extracellular $\alpha$-synuclein: a novel and crucial factor in Lewy body diseases. Nat Rev Neurol. 2014;10:92-98.

118. Dauer W, Przedborski S. Parkinson's disease: mechanisms and models. Neuron. 2003;39:889-909.

119. Nagatsu T, Sawada M. L-dopa therapy for Parkinson's disease: past, present, and future. Parkinsonism Relat Disord. 2009;15:S3-S8

120. Black KJ, Carl JL, Hartlein JM, Warren SL, Hershey T, Perlmutter JS. Rapid intravenous loading of levodopa for human research: clinical results. J Neurosci Methods. 2003;127:19-29.

121. Lin LF, Doherty DH, Lile JD, Bektesh S, Collins F. GDNF: a glial cell line-derived neurotrophic factor for midbrain dopaminergic neurons. Science. 1993;260:1130-1132.

122. Gash DM, Zhang Z, Gerhardt G. Neuroprotective and neurorestorative properties of GDNF. Ann Neurol. 1998;44:S121-S125.

123. Grondin R, Gash DM. Glial cell line-derived neurotrophic factor (GDNF): a drug candidate for the treatment of Parkinson's disease. J Neurol. 1998;245:P35-P42.

124. Hurelbrink CB, Barker RA. The potential of GDNF as a treatment for Parkinson's disease. Exp Neurol. 2004;185:1-6.

125. Wang Y, Xu H, Fu Q, Ma R, Xiang J. Protective effect of resveratrol derived from Polygonum cuspidatum and its liposomal form on nigral cells in parkinsonian rats. J Neurol Sci. 2011;304:29-34.

126. Amicarelli F, Gasbarri A, Masciocco L, et al. The effect of intrastriatal injection of liposome-entrapped tyrosinase on the dopamine levels in the rat brain. Cell Mol Biol (Noisy-le-Grand). 1999;45:1093-1097.

127. Segovia J, Vergara P, Brenner M. Astrocyte-specific expression of tyrosine hydroxylase after intracerebral gene transfer induces behavioral recovery in experimental parkinsonism. Gene Ther. 1998;5:1650-1655

128. Imaoka T, Date I, Ohmoto T, Nagatsu T. Significant behavioral recovery in Parkinson's disease model by direct intracerebral gene transfer using continuous injection of a plasmid DNA-liposome complex. Hum Gene Ther. 1998;9:1093-1102.

129. During MJ, Freese A, Deutch AY, et al. Biochemical and behavioral recovery in a rodent model of Parkinson's disease following stereotactic implantation of dopamine-containing liposomes. Exp Neurol. 1992;115:193-199. 
130. Campos-Romo A, Ojeda-Flores R, Moreno-Briseño P, et al. Behavioral improvement in MPTP-treated nonhuman primates in the HALLWAY task after transfer of TH cDNA to host astrocytes. Acta Neurobiol Exp (Wars). 2012;72:166-176.

131. Go AS, Mozaffarian D, Roger VL, et al. Executive summary: heart disease and stroke statistics - 2014 update: a report from the American Heart Association. Circulation. 2014;129:399-410.

132. Lo EH, Dalkara T, Moskowitz MA. Mechanisms, challenges and opportunities in stroke. Nat Rev Neurosci. 2003;4:399-415.

133. Yan J, Zheng M, Zhang D. Chrysophanol liposome preconditioning protects against cerebral ischemia-reperfusion injury by inhibiting oxidative stress and apoptosis in mice. Int J Pharmacol. 2014;10:55-68.

134. Deddens LH, van Tilborg GA, van der Toorn A, et al. MRI of ICAM-1 upregulation after stroke: the importance of choosing the appropriate target-specific particulate contrast agent. Mol Imaging Biol. 2013;15:411-422.

135. Liu S, Zhen G, Li RC, Doré S. Acute bioenergetic intervention or pharmacological preconditioning protects neuron against ischemic injury. J Exp Stroke Transl Med. 2013;6:7-17.

136. Yun X, Maximov VD, Yu J, Zhu H, Vertegel AA, Kindy MS. Nanoparticles for targeted delivery of antioxidant enzymes to the brain after cerebral ischemia and reperfusion injury. J Cereb Blood Flow Metab. 2013;33:583-592.

137. Dvoriantchikova G, Barakat DJ, Hernandez E, Shestopalov VI, Ivanov D. Liposome-delivered ATP effectively protects the retina against ischemia-reperfusion injury. Mol Vis. 2010;16:2882-2890.

138. Dvoriantchikova G, Agudelo C, Hernandez E, Shestopalov VI, Ivanov D. Phosphatidylserine-containing liposomes promote maximal survival of retinal neurons after ischemic injury. J Cereb Blood Flow Metab. 2009;29:1755-1759.

139. Chan PH. Antioxidant-dependent amelioration of brain injury: role of CuZn-superoxide dismutase. J Neurotrauma. 1992;9:S417-S423.

140. Hwang H, Jeong HS, Oh PS, et al. Improving cerebral blood flow through liposomal delivery of angiogenic peptides: potential of ${ }^{18} \mathrm{~F}$-FDG PET imaging in ischemic stroke treatment. $\mathrm{J} \mathrm{Nucl} \mathrm{Med}$. 2015;56:1106-1111.

141. Wang Z, Zhao Y, Jiang Y, et al. Enhanced anti-ischemic stroke of ZL006 by T7-conjugated PEGylated liposomes drug delivery system. Sci Rep. 2015;5:12651.

142. Agulla J, Brea D, Campos F, et al. In vivo theranostics at the periinfarct region in cerebral ischemia. Theranostics. 2014;4:90-105.

143. Fukuta T, Ishii T, Asai T, et al. Real-time trafficking of PEGylated liposomes in the rodent focal brain ischemia analyzed by positron emission tomography. Artif Organs. 2014;38:662-666.

144. Kaneda S, Ishizuka T, Sekiguchi A, Morimoto K, Kasukawa H. Efficacy of liposome-encapsulated hemoglobin in a rat model of cerebral ischemia. Artif Organs. 2014;38:650-655.

145. Kawaguchi AT, Endo H, Aikawa H, et al. Effects of liposomeencapsulated hemoglobin on learning ability in Tokai high-avoider rat after total brain ischemia and reperfusion. Artif Organs. 2014;38: $667-674$

146. Kim H, Britton GL, Peng T, et al. Nitric oxide-loaded echogenic liposomes for treatment of vasospasm following subarachnoid hemorrhage. Int J Nanomedicine. 2013;9:155-165.

147. Shimbo D, Abumiya T, Shichinohe H, Nakayama N, Kazumata K, Houkin K. Post-ischemic intra-arterial infusion of liposome-encapsulated hemoglobin can reduce ischemia reperfusion injury. Brain Res. 2014; 1554:59-66.

148. Ishii T, Fukuta T, Agato Y, et al. Nanoparticles accumulate in ischemic core and penumbra region even when cerebral perfusion is reduced. Biochem Biophys Res Commun. 2013;430:1201-1205.

149. Ishii T, Asai T, Oyama D, et al. Treatment of cerebral ischemiareperfusion injury with PEGylated liposomes encapsulating FK506. FASEB J. 2013;27:1362-1370.

150. Peng T, Britton GL, Kim H, et al. Therapeutic time window and dose dependence of xenon delivered via echogenic liposomes for neuroprotection in stroke. CNS Neurosci Ther. 2013;19:773-784.
151. Qu C, Ni J, Yang P, et al. Altered plasma and brain disposition of isopropylidene shikimic acid liposome in rats and the brain protection in cerebral ischemia-reperfusion. Drug Dev Ind Pharm. 2013;39: 1291-1295.

152. Ishii T, Asai T, Oyama D, et al. Amelioration of cerebral ischemiareperfusion injury based on liposomal drug delivery system with asialo-erythropoietin. J Control Release. 2012;160:81-87.

153. Ishii T, Asai T, Fukuta T, et al. A single injection of liposomal asialoerythropoietin improves motor function deficit caused by cerebral ischemia/reperfusion. Int J Pharm. 2012;439:269-274.

154. Tiebosch IA, Crielaard BJ, Bouts MJ, et al. Combined treatment with recombinant tissue plasminogen activator and dexamethasone phosphate-containing liposomes improves neurological outcome and restricts lesion progression after embolic stroke in rats. J Neurochem. 2012;123:65-74.

155. Ramos-Cabrer P, Agulla J, Argibay B, Pérez-Mato M, Castillo J. Serial MRI study of the enhanced therapeutic effects of liposomeencapsulated citicoline in cerebral ischemia. Int J Pharm. 2011;405: 228-233.

156. Zhao G, Zang SY, Jiang ZH, et al. Postischemic administration of liposome-encapsulated luteolin prevents against ischemia-reperfusion injury in a rat middle cerebral artery occlusion model. J Nutr Biochem. 2011;22:929-936.

157. Zhao H, Bao XJ, Wang RZ, et al. Postacute ischemia vascular endothelial growth factor transfer by transferrin-targeted liposomes attenuates ischemic brain injury after experimental stroke in rats. Hum Gene Ther. 2011;22:207-215.

158. Britton GL, Kim H, Kee PH, et al. In vivo therapeutic gas delivery for neuroprotection with echogenic liposomes. Circulation. 2010; 122:1578-1587.

159. Ghosh S, Das N, Mandal AK, Dungdung SR, Sarkar S. Mannosylated liposomal cytidine $5^{\prime}$ diphosphocholine prevent age related global moderate cerebral ischemia reperfusion induced mitochondrial cytochrome $\mathrm{C}$ release in aged rat brain. Neuroscience. 2010;171:1287-1299.

160. Hamadate N, Yamaguchi T, Sugawara A, et al. Liposome-encapsulated hemoglobin ameliorates impairment of fear memory and hippocampal dysfunction after cerebral ischemia in rats. J Pharmacol Sci. 2010;114:409-419.

161. Kakehata J, Yamaguchi T, Togashi H, et al. Therapeutic potentials of an artificial oxygen-carrier, liposome-encapsulated hemoglobin, for ischemia/reperfusion-induced cerebral dysfunction in rats. J Pharmacol Sci. 2010;114:189-197.

162. Fukumoto D, Kawaguchi AT, Haida M, Yamano M, Ogata Y, Tsukada H. Liposome-encapsulated hemoglobin reduces the size of cerebral infarction in rats: effect of oxygen affinity. Artif Organs. 2009;33: $159-163$

163. Kawaguchi AT, Kurita D, Furuya H, Yamano M, Ogata Y, Haida M. Liposome-encapsulated hemoglobin alleviates brain edema after permanent occlusion of the middle cerebral artery in rats. Artif Organs. 2009;33:153-158.

164. Urakami T, Kawaguchi AT, Akai S, et al. In vivo distribution of liposome-encapsulated hemoglobin determined by positron emission tomography. Artif Organs. 2009;33:164-168.

165. Omae T, Yoshioka H, Tanaka T, et al. Antisense in vivo knockdown of synaptotagmin I by HVJ-liposome mediated gene transfer attenuates ischemic brain damage in neonatal rats. Brain Dev. 2008; 30:313-320.

166. Rivera F, Costa G, Abin A, et al. Reduction of ischemic brain damage and increase of glutathione by a liposomal preparation of quercetin in permanent focal ischemia in rats. Neurotox Res. 2008;13:105-114.

167. Kawaguchi AT, Fukumoto D, Haida M, Ogata Y, Yamano M, Tsukada H. Liposome-encapsulated hemoglobin reduces the size of cerebral infarction in the rat: evaluation with photochemically induced thrombosis of the middle cerebral artery. Stroke. 2007;38:1626-1632.

168. Sarkar S, Das N. Mannosylated liposomal flavonoid in combating age-related ischemia-reperfusion induced oxidative damage in rat brain. Mech Ageing Dev. 2006;127:391-397. 
169. Adibhatla RM, Hatcher JF, Tureyen K. CDP-choline liposomes provide significant reduction in infarction over free CDP-choline in stroke. Brain Res. 2005;1058:193-197.

170. Luk YO, Chen WY, Wong WJ, et al. Treatment of focal cerebral ischemia with liposomal nerve growth factor. Drug Deliv. 2004;11: 319-324.

171. Oda T, Kimura T, Ogata Y, Fujise Y. Hemodilution with liposomeencapsulated low-oxygen-affinity hemoglobin does not attenuate hypothermic cerebral ischemia in rats. J Artif Organs. 2005;8:263-269.

172. Asahi M, Rammohan R, Sumii T, et al. Antiactin-targeted immunoliposomes ameliorate tissue plasminogen activator-induced hemorrhage after focal embolic stroke. J Cereb Blood Flow Metab. 2003;23: 895-899.

173. Omori N, Maruyama K, Jin G, et al. Targeting of post-ischemic cerebral endothelium in rat by liposomes bearing polyethylene glycolcoupled transferrin. Neurol Res. 2003;25:275-279.

174. Cao YJ, Shibata T, Rainov N. Liposome-mediated transfer of the bcl-2 gene results in neuroprotection after in vivo transient focal cerebral ischemia in an animal model. Gene Ther. 2002;9:415-419.

175. Sinha J, Das N, Basu MK. Liposomal antioxidants in combating ischemia-reperfusion injury in rat brain. Biomed Pharmacother. 2001; $55: 264-271$.

176. Takanashi Y, Ishida T, Kirchmeier MJ, Shuaib A, Allen TM. Neuroprotection by intrathecal application of liposome-entrapped fasudil in a rat model of ischemia. Neurol Med Chir (Tokyo). 2001;41: 107-114.

177. Fresta M, Puglisi G. Reduction of maturation phenomenon in cerebral ischemia with CDP-choline-loaded liposomes. Pharm Res. 1999;16: 1843-1849

178. Yokota M, Tani E, Tsubuki S, et al. Calpain inhibitor entrapped in liposome rescues ischemic neuronal damage. Brain Res. 1999;819: 8-14.

179. Fresta M, Puglisi G. Survival rate improvement in a rat ischemia model by long circulating liposomes containing cytidine-5I-diphosphate choline. Life Sci. 1997;61:1227-1235.

180. Fresta M. Biological effects of CDP-choline loaded long circulating liposomes on rat cerebral post-ischemic reperfusion. Int J Pharm. 1996;134:89-97.

181. Fresta M, Wehrli E, Puglisi G. Enhanced therapeutic effect of cytidine5 '-diphosphate choline when associated with GM1 containing small liposomes as demonstrated in a rat ischemia model. Pharm Res. 1995;12:1769-1774.

182. Fresta M, Puglisi G, Di Giacomo C, Russo A. Liposomes as in-vivo carriers for citicoline: effects on rat cerebral post-ischaemic reperfusion. J Pharm Pharmacol. 1994;46:974-981.

183. Puisieux F, Fattal E, Lahiani M, et al. Liposomes, an interesting tool to deliver a bioenergetic substrate (ATP): in vitro and in vivo studies. J Drug Target. 1994;2:443-448.

184. Chapat S, Frey V, Claperon N, et al. Efficiency of liposomal ATP in cerebral ischemia: bioavailability features. Brain Res Bull. 1991;26: 339-342.

185. Phelan AM, Lange DG. Ischemia/reperfusion-induced changes in membrane fluidity characteristics of brain capillary endothelial cells and its prevention by liposomal-incorporated superoxide dismutase. Biochim Biophys Acta. 1991;1067:97-102.

186. Imaizumi S, Woolworth V, Fishman RA, Chan PH. Liposomeentrapped superoxide dismutase reduces cerebral infarction in cerebral ischemia in rats. Stroke. 1990;21:1312-1317.

187. Laham A, Claperon N, Durussel JJ, et al. Intracarotidal administration of liposomally-entrapped ATP: improved efficiency against experimental brain ischemia. Pharmacol Res Commun. 1988;20:699-705.

188. Laham A, Claperon N, Durussel JJ, et al. Liposomally entrapped adenosine triphosphate: improved efficiency against experimental brain ischaemia in the rat. J Chromatogr. 1988;440:455-458.

189. Chan PH, Fishman RA, Wesley MA, Longar S. Pathogenesis of vasogenic edema in focal cerebral ischemia: role of superoxide radicals. Adv Neurol. 1990;52:177-183.
190. Bigon E, Boarato E, Bruni A, Leon A, Toffano G. Pharmacological effects of phosphatidylserine liposomes: regulation of glycolysis and energy level in brain. Br J Pharmacol. 1979;66:167-174.

191. Komatsu H, Furuya T, Sato N, et al. Effect of hemoglobin vesicle, a cellular-type artificial oxygen carrier, on middle cerebral artery occlusion- and arachidonic acid-induced stroke models in rats. Neurosci Lett. 2007;421:121-125.

192. Stanimirovic DB, Markovic M, Micic DV, Spatz M, Mrsulja BB. Liposome-entrapped superoxide dismutase reduces ischemia/ reperfusion 'oxidative stress' in gerbil brain. Neurochem Res. 1994;19: 1473-1478

193. Kawaguchi AT, Haida M, Ohba H, Yamano M, Fukumoto D, Tsukada H. Liposome-encapsulated hemoglobin ameliorates ischemic stroke in nonhuman primates: longitudinal observation. Artif Organs 2013;37:904-912.

194. Kawaguchi AT, Haida M, Yamano M, Fukumoto D, Ogata Y, Tsukada H. Liposome-encapsulated hemoglobin ameliorates ischemic stroke in nonhuman primates: an acute study. J Pharmacol Exp Ther. 2010;332:429-436

195. Wardlaw JM, Murray V, Berge E, et al. Recombinant tissue plasminogen activator for acute ischaemic stroke: an updated systematic review and meta-analysis. Lancet. 2012;379:2364-2372.

196. Lichtman JH, Krumholz HM, Wang Y, Radford MJ, Brass LM. Risk and predictors of stroke after myocardial infarction among the elderly: results from the Cooperative Cardiovascular Project. Circulation. 2002; 105:1082-1087.

197. Overgaard K. The effects of citicoline on acute ischemic stroke: a review. J Stroke Cerebrovasc Dis. 2014;23:1764-1769.

198. Secades J. Citicoline: pharmacological and clinical review - 2010 update. Rev Neurol. 2011;52:S1-S62.

199. Navaratna D, Guo S, Arai K, Lo EH. Mechanisms and targets for angiogenic therapy after stroke. Cell Adh Migr. 2009;3: 216-223.

200. Schwartzbaum JA, Fisher JL, Aldape KD, Wrensch M. Epidemiology and molecular pathology of glioma. Nat Clin Pract Neurol. 2006; 2:494-503

201. Minniti G, De Sanctis V, Muni R, et al. Radiotherapy plus concomitant and adjuvant temozolomide for glioblastoma in elderly patients. J Neurooncol. 2008;88:97-103.

202. Wei X, Chen X, Ying M, Lu W. Brain tumor-targeted drug delivery strategies. Acta Pharm Sin B. 2014;4:193-201.

203. Ju RJ, Zeng F, Liu L, et al. Destruction of vasculogenic mimicry channels by targeting epirubicin plus celecoxib liposomes in treatment of brain glioma. Int J Nanomedicine. 2016;11:1131-1146.

204. Liu Y, Mei L, Xu C, et al. Dual receptor recognizing cell penetrating peptide for selective targeting, efficient intratumoral diffusion and synthesized anti-glioma therapy. Theranostics. 2016;6: $177-191$.

205. Shi K, Long Y, Xu C, et al. Liposomes combined an integrin $\alpha v \beta 3$ specific vector with $\mathrm{pH}$-responsible cell-penetrating property for highly effective antiglioma therapy through the blood-brain barrier. ACS Appl Mater Interfaces. 2015;7:21442-21454.

206. Costa PM, Cardoso AL, Custódia C, et al. MiRNA-21 silencing mediated by tumor-targeted nanoparticles combined with sunitinib: a new multimodal gene therapy approach for glioblastoma. J Control Release. 2015;207:31-39.

207. Liu Y, Mei L, Yu Q, et al. Multifunctional tandem peptide modified paclitaxel-loaded liposomes for the treatment of vasculogenic mimicry and cancer stem cells in malignant glioma. ACS Appl Mater Interfaces 2015;7:16792-16801.

208. Pacheco-Torres J, Mukherjee N, Walko M, et al. Image guided drug release from $\mathrm{pH}$-sensitive ion channel-functionalized stealth liposomes into an in vivo glioblastoma model. Nanomedicine. 2015; 11:1345-1354.

209. Peiris PM, Abramowski A, Mcginnity J, et al. Treatment of invasive brain tumors using a chain-like nanoparticle. Cancer Res. 2015;75: 1356-1365. 
210. Li XT, Ju RJ, Li XY, et al. Multifunctional targeting daunorubicin plus quinacrine liposomes, modified by wheat germ agglutinin and tamoxifen, for treating brain glioma and glioma stem cells. Oncotarget. 2014;5:6497-6511.

211. Qin L, Wang CZ, Fan HJ, et al. A dual-targeting liposome conjugated with transferrin and arginine-glycine-aspartic acid peptide for gliomatargeting therapy. Oncol Lett. 2014;8:2000-2006.

212. Yang Z, Xiang B, Dong D, Wang Z, Li J, Qi X. Dual receptor-specific peptides modified liposomes as VEGF siRNA vector for tumortargeting therapy. Curr Gene Ther. 2014;14:289-299.

213. Zong T, Mei L, Gao H, et al. Enhanced glioma targeting and penetration by dual-targeting liposome co-modified with T7 and TAT. J Pharm Sci. 2014;103:3891-3901.

214. Chen PY, Ozawa T, Drummond DC, et al. Comparing routes of delivery for nanoliposomal irinotecan shows superior anti-tumor activity of local administration in treating intracranial glioblastoma xenografts. Neuro Oncol. 2013;15:189-197.

215. Costa PM, Cardoso AL, Mendonça LS, et al. Tumor-targeted chlorotoxin-coupled nanoparticles for nucleic acid delivery to glioblastoma cells: a promising system for glioblastoma treatment. Mol Ther Nucleic Acids. 2013;2:e100.

216. Yang Y, Yan Z, Wei D, et al. Tumor-penetrating peptide functionalization enhances the anti-glioblastoma effect of doxorubicin liposomes. Nanotechnology. 2013;24:405101.

217. Huang Y, Zhou D, Hang T, et al. Preparation, characterization, and assessment of the antiglioma effects of liposomal celastrol. Anticancer Drugs. 2012;23:515-524.

218. Gong W, Wang Z, Liu N, et al. Improving efficiency of adriamycin crossing blood brain barrier by combination of thermosensitive liposomes and hyperthermia. Biol Pharm Bull. 2011;34:1058-1064.

219. Mei DY, Gao HL, Gong WH, Pang ZQ, Jiang XG, Chen J. Anti-glioma effect of doxorubicin loaded liposomes modified with angiopep-2. Afr J Pharm Pharmacol. 2011;5:409-414.

220. Serwer LP, Noble CO, Michaud K, et al. Investigation of intravenous delivery of nanoliposomal topotecan for activity against orthotopic glioblastoma xenografts. Neuro Oncol. 2011;13:1288-1295.

221. Xiang Y, Liang L, Wang X, Wang J,Zhang X, Zhang Q. Chloride channelmediated brain glioma targeting of chlorotoxin-modified doxorubicineloaded liposomes. J Control Release. 2011;152:402-410.

222. Feng B, Tomizawa K, Michiue H, et al. Delivery of sodium borocaptate to glioma cells using immunoliposome conjugated with anti-EGFR antibodies by ZZ-His. Biomaterials. 2009;30:1746-1755.

223. Madhankumar AB, Slagle-Webb B, Wang X, et al. Efficacy of interleukin-13 receptor-targeted liposomal doxorubicin in the intracranial brain tumor model. Mol Cancer Ther. 2009;8:648-654.

224. Doi A, Kawabata S, Iida K, et al. Tumor-specific targeting of sodium borocaptate $(\mathrm{BSH})$ to malignant glioma by transferrin-PEG liposomes: a modality for boron neutron capture therapy. J Neurooncol. 2008;87:287-294.

225. Abounader R, Lal B, Luddy $\mathrm{C}$, et al. In vivo targeting of $\mathrm{SF} / \mathrm{HGF}$ and c-met expression via U1snRNA/ribozymes inhibits glioma growth and angiogenesis and promotes apoptosis. FASEB J. 2002;16:108-110.

226. Lin Q, Mao KL, Tian FR, et al. Brain tumor-targeted delivery and therapy by focused ultrasound introduced doxorubicin-loaded cationic liposomes. Cancer Chemother Pharmacol. 2016;77:269-280.

227. Mabuchi E, Shimizu K, Miyao Y, et al. Gene delivery by HVJliposome in the experimental gene therapy of murine glioma. Gene Ther. 1997;4:768-772.

228. Aryal M, Park J, Vykhodtseva N, Zhang YZ, McDannold N. Enhancement in blood-tumor barrier permeability and delivery of liposomal doxorubicin using focused ultrasound and microbubbles: evaluation during tumor progression in a rat glioma model. Phys Med Biol. 2015;60:2511-2527.

229. Huang FY, Lee TW, Chang CH, et al. Evaluation of 188 Re-labeled PEGylated nanoliposome as a radionuclide therapeutic agent in an orthotopic glioma-bearing rat model. Int J Nanomedicine. 2015;10: $463-473$.
230. Mendiburu-Eliçabe M, Gil-Ranedo J. Combination therapy of intraperitoneal rapamycin and convection-enhanced delivery of nanoliposomal CPT-11 in rodent orthotopic brain tumor xenografts. Curr Cancer Drug Targets. 2015;15:352-362.

231. Qiu LH, Zhang JW, Li SP, et al. Molecular imaging of angiogenesis to delineate the tumor margins in glioma rat model with endoglin-targeted paramagnetic liposomes using 3T MRI. J Magn Reson Imaging. 2015;41:1056-1064.

232. Roller BT, Munson JM, Brahma B, Santangelo PJ, Pai SB, Bellamkonda RV. Evans blue nanocarriers visually demarcate margins of invasive gliomas. Drug Deliv Transl Res. 2015;5:116-124.

233. Shein SA, Nukolova NV, Korchagina AA, et al. Site-directed delivery of VEGF-targeted liposomes into intracranial C6 glioma. Bull Exp Biol Med. 2015;158:371-376.

234. Li XY, Zhao Y, Sun MG, et al. Multifunctional liposomes loaded with paclitaxel and artemether for treatment of invasive brain glioma. Biomaterials. 2014;35:5591-5604.

235. Noble CO, Krauze MT, Drummond DC, et al. Pharmacokinetics, tumor accumulation and antitumor activity of nanoliposomal irinotecan following systemic treatment of intracranial tumors. Nanomedicine (Lond). 2014;9:2099-2108.

236. Yue PJ, He L, Qiu SW, et al. OX26/CTX-conjugated PEGylated liposome as a dual-targeting gene delivery system for brain glioma. Mol Cancer. 2014;13:191.

237. Charest G, Sanche L, Fortin D, Mathieu D, Paquette B. Optimization of the route of platinum drugs administration to optimize the concomitant treatment with radiotherapy for glioblastoma implanted in the Fischer rat brain. $J$ Neurooncol. 2013;115:365-373.

238. Gao JQ, Lv Q, Li LM, et al. Glioma targeting and blood-brain barrier penetration by dual-targeting doxorubincin [sic] liposomes. Biomaterials. 2013;34:5628-5639.

239. Chekhonin VP, Baklaushev VP, Yusubalieva GM, et al. Targeted delivery of liposomal nanocontainers to the peritumoral zone of glioma by means of monoclonal antibodies against GFAP and the extracellular loop of Cx43. Nanomedicine. 2012;8:63-70.

240. Huo T, Barth RF, Yang W, et al. Preparation, biodistribution and neurotoxicity of liposomal cisplatin following convection enhanced delivery in normal and F98 glioma bearing rats. PLoS One. 2012;7: e48752.

241. Munson JM, Fried L, Rowson SA, et al. Anti-invasive adjuvant therapy with imipramine blue enhances chemotherapeutic efficacy against glioma. Sci Transl Med. 2012;4:127ra36.

242. Phillips WT, Goins B, Bao A, et al. Rhenium-186 liposomes as convection-enhanced nanoparticle brachytherapy for treatment of glioblastoma. Neuro Oncol. 2012;14:416-425.

243. Treat LH, McDannold N, Zhang Y, Vykhodtseva N, Hynynen K. Improved anti-tumor effect of liposomal doxorubicin after targeted blood-brain barrier disruption by MRI-guided focused ultrasound in rat glioma. Ultrasound Med Biol. 2012;38:1716-1725.

244. Chen H, Qin Y, Zhang Q, et al. Lactoferrin modified doxorubicinloaded procationic liposomes for the treatment of gliomas. Eur $J$ Pharm Sci. 2011;44:164-173.

245. Huang FY, Lee TW, Kao $\mathrm{CH}$, et al. Imaging, autoradiography, and biodistribution of 188 re-labeled PEGylated nanoliposome in orthotopic glioma bearing rat model. Cancer Biother Radiopharm. 2011; 26:717-725

246. Miyata S, Kawabata S, Hiramatsu R, et al. Computed tomography imaging of transferrin targeting liposomes encapsulating both boron and iodine contrast agents by convection-enhanced delivery to F98 rat glioma for boron neutron capture therapy. Neurosurgery. 2011; 68:1380-1387.

247. Oku N, Yamashita M, Katayama Y, et al. PET imaging of brain cancer with positron emitter-labeled liposomes. Int J Pharm. 2011; 403:170-177.

248. Qin Y, Chen H, Zhang Q, et al. Liposome formulated with TAT-modified cholesterol for improving brain delivery and therapeutic efficacy on brain glioma in animals. Int J Pharm. 2011;420:304-312. 
249. Tian W, Ying X, Du J, et al. Enhanced efficacy of functionalized epirubicin liposomes in treating brain glioma-bearing rats. Eur J Pharm Sci. 2010;41:232-243.

250. Ying X, Wen H, Lu WL, et al. Dual-targeting daunorubicin liposomes improve the therapeutic efficacy of brain glioma in animals. J Control Release. 2010;141:183-192.

251. Du J, Lu WL, Ying X, et al. Dual-targeting topotecan liposomes modified with tamoxifen and wheat germ agglutinin significantly improve drug transport across the blood-brain barrier and survival of brain tumor-bearing animals. Mol Pharm. 2009;6:905-917.

252. Grahn AY, Bankiewicz KS, Dugich-Djordjevic M, et al. Non-PEGylated liposomes for convection-enhanced delivery of topotecan and gadodiamide in malignant glioma: initial experience. J Neurooncol. 2009;95:185-197.

253. Zhang D, Feng XY, Henning TD, et al. MR imaging of tumor angiogenesis using sterically stabilized Gd-DTPA liposomes targeted to CD105. Eur J Radiol. 2009;70:180-189.

254. Karathanasis E, Park J, Agarwal A, et al. MRI mediated, non-invasive tracking of intratumoral distribution of nanocarriers in rat glioma. Nanotechnology. 2008;19:315101.

255. Zhao S, Zhang X, Zhang J, et al. Intravenous administration of arsenic trioxide encapsulated in liposomes inhibits the growth of C6 gliomas in rat brains. $J$ Chemother. 2008;20:253-262.

256. Huynh GH, Ozawa T, Deen DF, Tihan T, Szoka FC Jr. Retroconvection enhanced delivery to increase blood to brain transfer of macromolecules. Brain Res. 2007;1128:181-190.

257. Krauze MT, Noble CO, Kawaguchi T, et al. Convection-enhanced delivery of nanoliposomal CPT-11 (irinotecan) and PEGylated liposomal doxorubicin (Doxil) in rodent intracranial brain tumor xenografts. Neuro Oncol. 2007;9:393-403.

258. Yamashita Y, Krauze MT, Kawaguchi T, et al. Convection-enhanced delivery of a topoisomerase I inhibitor (nanoliposomal topotecan) and a topoisomerase II inhibitor (PEGylated liposomal doxorubicin) in intracranial brain tumor xenografts. Neuro Oncol. 2006;9:20-28.

259. Noble CO, Krauze MT, Drummond DC, et al. Novel nanoliposomal CPT-11 infused by convection-enhanced delivery in intracranial tumors: pharmacology and efficacy. Cancer Res. 2006;66: 2801-2806

260. Saito R. Convection-enhanced delivery of Ls-TPT enables an effective, continuous, low-dose chemotherapy against malignant glioma xenograft model. Neuro Oncol. 2006;8:205-214.

261. Mamot C, Nguyen JB, Pourdehnad M, et al. Extensive distribution of liposomes in rodent brains and brain tumors following convectionenhanced delivery. J Neurooncol. 2004;68:1-9.

262. Saito R, Bringas JR, McKnight TR, et al. Distribution of liposomes into brain and rat brain tumor models by convection-enhanced delivery monitored with magnetic resonance imaging. Cancer Res. 2004; $64: 2572-2579$.

263. Zhang Y, Boado RJ, Pardridge WM. In vivo knockdown of gene expression in brain cancer with intravenous RNAi in adult rats. $J$ Gene Med. 2003;5:1039-1045.

264. Jiang F, Lilge L, Grenier J, Li Y, Wilson MD, Chopp M. Photodynamic therapy of U87 human glioma in nude rat using liposome-delivered photofrin. Lasers Surg Med. 1998;22:74-80.

265. Ho SY, Barbarese E, D’Arrigo JS, Smith-Slatas C, Simon RH. Evaluation of lipid-coated microbubbles as a delivery vehicle for Taxol in brain tumor therapy. Neurosurgery. 1997;40:1260-1268.

266. Jiang F, Lilge L, Logie B, Li Y, Chopp M. Photodynamic therapy of 9L gliosarcoma with liposome-delivered photofrin. Photochem Photobiol. 1997;65:701-706.

267. Sharma US, Sharma A, Chau RI, Straubinger RM. Liposome-mediated therapy of intracranial brain tumors in a rat model. Pharm Res. 1997; 14:992-998.

268. Kakinuma K, Tanaka R, Takahashi H, Watanabe M, Nakagawa T, Kuroki M. Targeting chemotherapy for malignant brain tumor using thermosensitive liposome and localized hyperthermia. J Neurosurg. 1996;84:180-184.
269. Barbarese E, Ho SY, D'Arrigo JS, Simon RH. Internalization of microbubbles by tumor cells in vivo and in vitro. J Neurooncol. 1995; 26:25-34.

270. Shibata S, Ochi A, Mori K. Liposomes as carriers of cisplatin into the central nervous system: experiments with 9L gliomas in rats. Neurol Med Chir (Tokyo). 1990;30:242-245.

271. Zhang H, Wen Y, Mao B, Gong Q, Qian Z, Wei Y. Plasmid encoding matrix protein of vesicular stomatitis viruses as an antitumor agent inhibiting rat glioma growth in situ. Exp Oncol. 2007;29:85-93.

272. Dickinson PJ, LeCouteur RA, Higgins RJ, et al. Canine spontaneous glioma: a translational model system for convection-enhanced delivery. Neuro Oncol. 2010;12:928-940.

273. Krauze MT, Mcknight TR, Yamashita Y, et al. Real-time visualization and characterization of liposomal delivery into the monkey brain by magnetic resonance imaging. Brain Res Brain Res Protoc. 2005; 16:20-26.

274. Wakabayashi T, Natsume A, Hashizume Y, Fujii M, Mizuno M, Yoshida J. A phase I clinical trial of interferon-beta gene therapy for high-grade glioma: novel findings from gene expression profiling and autopsy. J Gene Med. 2008;10:329-339.

275. Fiorillo A, Maggi G, Greco N, et al. Second-line chemotherapy with the association of liposomal daunorubicin, carboplatin and etoposide in children with recurrent malignant brain tumors. JNeurooncol. 2004; 66:179-185.

276. Yoshida J, Mizuno M, Fujii M, et al. Human gene therapy for malignant gliomas (glioblastoma multiforme and anaplastic astrocytoma) by in vivo transduction with human interferon beta gene using cationic liposomes. Hum Gene Ther. 2004;15:77-86.

277. Ren H, Boulikas T, Lundstrom K, Söling A, Warnke PC, Rainov NG. Immunogene therapy of recurrent glioblastoma multiforme with a liposomally encapsulated replication-incompetent Semliki forest virus vector carrying the human interleukin-12 gene: a phase I/II clinical protocol. J Neurooncol. 2003;64:147-154.

278. Albrecht KW, de Witt Hamer PC, Leenstra S, et al. High concentration of daunorubicin and daunorubicinol in human malignant astrocytomas after systemic administration of liposomal daunorubicin. JNeurooncol. 2001;53:267-271.

279. Fabel K, Dietrich J, Hau P, et al. Long-term stabilization in patients with malignant glioma after treatment with liposomal doxorubicin Cancer. 2001;92:1936-1942.

280. Koukourakis MI, Koukouraki S, Fezoulidis I, et al. High intratumoural accumulation of stealth liposomal doxorubicin (Caelyx) in glioblastomas and in metastatic brain tumours. BrJ Cancer. 2000;83: 1281-1286.

281. Zucchetti M, Boiardi A, Silvani A, Parisi I, Piccolrovazzi S, D'Incalci M. Distribution of daunorubicin and daunorubicinol in human glioma tumors after administration of liposomal daunorubicin. Cancer Chemother Pharmacol. 1999;44:173-176.

282. Firth GB, Firth M, McKeran RO, et al. Application of radioimmunoassay to monitor treatment of human cerebral gliomas with bleomycin entrapped within liposomes. J Clin Pathol. 1988;41:38-43.

283. McKeran RO, Firth G, Oliver S, Uttley D, O'Laoire S. A potential application for the intracerebral injection of drugs entrapped within liposomes in the treatment of human cerebral gliomas. J Neurol Neurosurg Psychiatry. 1985;48:1213-1219.

284. Chapman S, Dobrovolskaia M, Farahani K, et al. Nanoparticles for cancer imaging: the good, the bad, and the promise. Nano Today. 2013; 8:454-460.

285. Keunen O, Taxt T, Grüner R, et al. Multimodal imaging of gliomas in the context of evolving cellular and molecular therapies. Adv Drug Deliv Rev. 2014;76:98-115.

286. Hernández-Pedro NY, Rangel-López E, Magaña-Maldonado R, et al. Application of nanoparticles on diagnosis and therapy in gliomas. Biomed Res Int. 2013;2013:351031.

287. Blasiak B, van Veggel FC, Tomanek B. Applications of nanoparticles for MRI cancer diagnosis and therapy. J Nanomater. 2013;2013: 148578 . 
288. Haglund MM, Berger MS, Hochman DW. Enhanced optical imaging of human gliomas and tumor margins. Neurosurgery. 1996;38: 308-317.

289. Minn H. PET and SPECT in low-grade glioma. Eur J Radiol. 2005; 56:171-178.

290. la Fougère C, Suchorska B, Bartenstein P, Kreth FW, Tonn JC. Molecular imaging of gliomas with PET: opportunities and limitations. Neuro Oncol. 2011;13:806-819.

291. Anderson JC, McFarland BC, Gladson CL. New molecular targets in angiogenic vessels of glioblastoma tumours. Expert Rev Mol Med. 2008; 10:e23.

292. Baskar R, Lee KA, Yeo R, Yeoh KW. Cancer and radiation therapy: current advances and future directions. Int J Med Sci. 2012;9:193-199.

293. Werner-Wasik M, Scott CB, Nelson DF, et al. Final report of a phase I/II trial of hyperfractionated and accelerated hyperfractionated radiation therapy with carmustine for adults with supratentorial malignant gliomas. Cancer. 1996;77:1535-1543.

294. Schwarz SB, Thon N, Nikolajek K, et al. Iodine-125 brachytherapy for brain tumours: a review. Radiat Oncol. 2012;7:30.
295. Thorn CF, Oshiro C, Marsh S, et al. Doxorubicin pathways: pharmacodynamics and adverse effects. Pharmacogenet Genomics. 2011;21: 440-446.

296. Yaqub F. Mechanism of action of anthracycline drugs. Lancet Oncol. 2013;14:e296.

297. Della Latta V, Cecchettini A, Del Ry S, Morales MA. Bleomycin in the setting of lung fibrosis induction: from biological mechanisms to counteractions. Pharmacol Res. 2015;97:122-130.

298. von Holst H, Knochenhauer E, Blomgren H, et al. Uptake of adriamycin in tumour and surrounding brain tissue in patients with malignant gliomas. Acta Neurochir (Wien). 1990;104:13-16.

299. Hervé F, Ghinea N, Scherrmann JM. CNS delivery via adsorptive transcytosis. AAPS J. 2008;10:455-472.

300. Zhan C, Lu W. The blood-brain/tumor barriers: challenges and chances for malignant gliomas targeted drug delivery. Curr Pharm Biotechnol. 2012;13:2380-2387.

301. Koo YE, Reddy GR, Bhojani M, et al. Brain cancer diagnosis and therapy with nanoplatforms. Adv Drug Deliv Rev. 2006;58: 1556-1577.
International Journal of Nanomedicine

\section{Publish your work in this journal}

The International Journal of Nanomedicine is an international, peerreviewed journal focusing on the application of nanotechnology in diagnostics, therapeutics, and drug delivery systems throughout the biomedical field. This journal is indexed on PubMed Central, MedLine, CAS, SciSearch $\AA$, Current Contents ${ }^{\circledR} /$ Clinical Medicine,

\section{Dovepress}

Journal Citation Reports/Science Edition, EMBase, Scopus and the Elsevier Bibliographic databases. The manuscript management system is completely online and includes a very quick and fair peer-review system, which is all easy to use. Visit http://www.dovepress.com/ testimonials.php to read real quotes from published authors. 